NBSIR 84-2983

\title{
Molecular Basis for Laser-Induced Vaporization of Refractory Materials
}

J. W. Hastie, D. W. Bonnell, and P. K. Schenck

U.S. DEPARTMENT OF COMMERCE National Bureau of Standards Center for Materials Science Inorganic Materials Division High Temperature Processes Group • Gaithersburg, MD 20899

\section{December 1984}

Annual Report

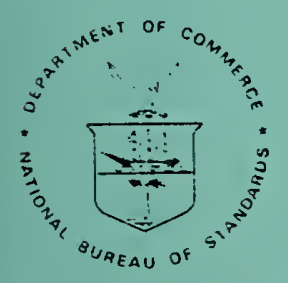

U.S. DEPARTMENT OF COMMERCE NATIONAL BUREAU OF STANDARDS 

NBSIR $84-2983$

MOLECULAR BASIS FOR LASER-INDUCED

VAPORIZATION OF REFRACTORY

MATERIALS

J. W. Hastie, D. W. Bonnell, and P. K. Schenck

U.S. DEPARTMENT OF COMMERCE

National Bureau of Standards

Center for Materials Science

Inorganic Materials Division

High Temperature Processes Group

Gaithersburg, MD 20899

December 1984

Annual Report

U.S. DEPARTMENT OF COMMERCE, Malcolm Baidrige, Secretary NATIONAL BUREAU OF STANDARDS. Emest Ambler, Director 

Molecular Basis for Laser-Induced Vaporization

of Refractory Materials

J. W. Hastie, D. W. Bonnell, and P. K. Schenck High Temperature Processes Group

Inorganic Materials Division

National Bureau of Standards

Gaithersburg, MD 20899 

1. Introduction and Summary

2. Subtask A: Results and Discussion

2.1 Aoparatus and Experimental Approach

2.2 Results

2.3 Temperature Determination

2.3.1 Beam Velocity Analysis

2.3.2 Species Intensity Analysis

2.4 Literature Studies of Laser-Induced Vaporization of Graphite 2.4.1 Literature Survey, for the Period 1968-1983

2.4.2 Literature Summary, for the Period 1968-1983

2.4.3 Literature Summary, for the Pre-1968 Period

2.4.4 Conclusions From the Literature Survey

\subsection{Carbon Vaporization from Carbides}

3. Subtask B: Cluster Formation Studies

4. Subtask C: Results on Ionization Processes

5. References

6. Tables

7. Figures 



\section{Molecular Basis for Laser-Induced Vaporization \\ of Refractory Materials \\ J. W. Hastie, D. W. Bonnell, and P. K. Schenck \\ High Temperature Processes Group \\ Inorganic Materials Division \\ Gaithersburg, MD 20899}

\section{Introduction and Summary}

The interaction of high power lasers with refractory materials has been studied by a number of workers during the last two decades. Most of these studies have concentrated on the macroscopic, non-molecular processes such as: crater formation, material removal rate, and plume dynamics. The objective of the present study is to provide a molecular-level description of the vaporization processes, and to provide a fundamental link to smoke and aerosol formation. These processes are central to the interaction of high power lasers with graphitic or other refractory materials. This report describes the results of research carried out during Fy84. The effort is divided into three interlinked subtasks, as follows:

- Subtask A: Laser Vaporization Kinetics of Carbon-Containing Refractories. Objective: To determine molecular specific mechanisms of laser-induced vaporization using high energy laser heating of surfaces, and timeresolved, high pressure sampling mass spectrometry of the vapor species produced.

- Subtask B: Mechanisms of Formation for Submicron Metal-Containing Particulates.

Objective: To follow aerosol formation from expanding high temperature vapors in a vacuum environment. Particular emphasis is given to the mechanism for homogeneous nucleation which results from aggregation of molecular species to form cluster intermediates and macroscopic particulates. 

- Subtask C: Ionization Processes.

Objective: To determine the influence of high temperature on molecular ionization processes, with emphasis on both partial and total electronimpact ionization cross-sections. A temperature dependence of these cross-sections would manifest itself in the electron impact fragmencation patterns of the $C_{n}(n=1-5)$ species, for instance, and could account for some of the disparate literature results on graphite vaporization thermodynamics.

of these areas, subtask $A$ is the primary effort, with subtask $C$ providing important information regarding mass spectral interpretation. Subtask $B$ deals with the link between the molecular-level initial vaporforming process and the macroscopic process of aerosol formation. The principal research carried out under these three subtasks, during FY84, is summarized as follows with additional details given in section 2 .

For subtask A, a Laser-Induced Vaporization (LIV) facility has been constructed and tested. The apparatus consists of a $10 \mathrm{~Hz}$, pulsed $\mathrm{Nd} / \mathrm{YAG}$ laser coupled to a specially designed high pressure sampling mass spectrometer. In principle, the mass spectrometer can detect both charged and neutral species arising from the laser vaporization process. However, under the conditions of the present study, where laser-vapor plume interaction was avoided as far as possible, only neutral species were observed. Thus the ions referred to here are those resulting from electron impact ionization of molecular species in the mass spectrometer ion-source. Initial studies on an uItra-pure spectroscopic grade graphite sample, provided quantitative time-resolved mass spectral peaks of $C_{n}(n=1-5)$ singly charged positive molecular ions with excellent signal-to-noise ratios and reproducibility. The absolute and relative concentrations of the corresponding neutral species were consistent 
with the establishment of local thermodynamic equiliorium at the sample "surface." The "surface" in these studies was actually slightly cratered by the focused laser beam, with a typical crater having dimensions of about 0.03 cm width and $0.01 \mathrm{~cm}$ depth. For minimum laser power $(10 \mathrm{~mJ})$ conditions, the surface temperature was determined indirectly from the mass spectral data to be $4100 \pm 300 K$ at a total species pressure of one atmosphere ( 1 atm $=$ $101,325 \mathrm{~Pa})$. A beam-velocity analysis of the $C_{n}$ species indicated an appreciable cooling effect (to $2500 \mathrm{~K}$ ) in the vapor plume by an adiabatic expansion process. Additional studies are needed to identify the processes occuring at a smooth surface, in comparison with those resulting from the shallow craters formed under the present experimental conditions. Planned experiments include:

- Traversing the sample surface between successive laser shots--to avoid crater-formation.

- Use of a rod-like sample geometry, with a cross section dimension matching that of the hot-spot--to provide for a complete surface regression as opposed to cratering.

- Data collection, at a fixed sample position, as a function of number of laser shots and, hence, crater size--to follow the transition between free (vaporization coefficient, $\propto \leqq 1$ ) and Knudsen-like (equilibrium, $\propto \equiv 1$ ) vaporization conditions.

Based on these initial results, obtained with the $10 \mathrm{~Hz} \mathrm{Nd/YAG} \mathrm{Iaser}$ system, and also earlier tests with a $\mathrm{CW} \mathrm{CO} 2$ laser, a new laser has been selected (and procured by NBS) for permanent coupling with the mass spectrometric system. This $20 \mathrm{~Hz}$ Nd/YAG laser has recently been optically coupled with the mass spectrometer. However, delivery and installation of the 
doubling crystals and the beam collimation telescopes, necessary to proper propagation or the beam, has been delayed (- 6 months) by the vendor, and the new system is not expected to be fully operational until early in 1985 .

Under subtask B, attempts to produce molecular clusters by non-equilibrium adiabatic expansion of NaCl, KCl, and $C_{n}(n=1-5)$ moiecuiar species showed no evidence of ciustering at source vapor pressures to one atmosphere. Apparently, higher pressures and longer expansion times (e.g., larger nozzles and lower expansion pressure-ratios) are needed to remove the appreciable excess energy produced in the initial aggregation process. It is also possible, though unlikely in the present case, that a small amount of clustering may remain undetected due to destruction of the clusters during the electron impact ionization process in the mass spectrometer. Additional studies are planned to determine the conditions needed for cluster formation and detection.

With regard to subtask $C$, we have found that the electron impact ionization cross-section $(\sigma)$ can vary quite significantly with temperature, particularly for species exhibiting a large geometry change on ionization. Data obtained for the test cases, $\mathrm{NaCl}$ and $\mathrm{KCl}$, exhibited large changes in $\sigma(25: 1)$ between high temperature $(-1000 \mathrm{~K})$ species and translationally cooled low temperature $(-50 \mathrm{~K})$ molecules. A quantitative potential energy curve model has been developed to account for this initially unexpected effect. The model has also been extended, on a qualitative basis, to allow for predictions of temperature dependent electron impact fragmentation with other high temperature species, including $C_{n}(n=1-5)$. Future studies will attempt to validate and improve the nodel. 
2. Subtask A: Laser Vaporization Kinetics of Carbon-Containing Refractories - Results and Discussion

2.1 Apparatus and Experimental Approach

The basic apparatus, developed especially for this subtask, is shown schematically in figure 1. Note that the laser, molecular beam orifices, and mass spectrometer are configured to reduce the possibility of laser interaction with the portion of vapor plume directed toward the mass spectrometer. Such an interaction could lead to ionization and plasma effects not characteristic of the vaporization process, as noted in earlier studies, e.g.', see Lincoln and Covington [1975]. The laser beam enters the first pumping stage of the Vertical High Pressure Sampling Mass Spectrometer (VHPMS) at right angles to the mass spectrometer beam 1 ine, as shown in figure 1 .

The laser system basically consists of an externally mounted $10 \mathrm{~Hz}$ Nd/YAG laser (very recently upgraded to $20 \mathrm{~Hz}$ ), operating at wavelengths from $1060 \mathrm{~nm}$ to $350 \mathrm{~nm}$. To allow for ready visual alignment of the beam, the 532. nm doubled line of the laser fundamental was chosen as the working wavelength for the present studies. The laser pulse time used was about 7 nsec, which is negligible on the time scale of the vaporization process. This process required about $0.5-1$ usec for a 10 percent change on the leading edge of the ion intensity-versus-time signal profile. Earlier studies, such as those of Ohse, et al., [1979], have indicated the utility of short pulse time, high power lasers (e.g., Nd/YAG) for controlled surface vaporization studies. The laser beam was focused onto the sample by a $500 \mathrm{~mm}$ focal length lens, mounted on a movable stage. A spot size of 250 microns was used. The laser was operated near threshold and adjusted to deliver the same power for each pulse in a data-averaging series. 
Figure 2 shows details of the Virms vacuum system. The viewpoint (normal to the page) is that of the entering laser beam. For the present study, the chopper, in stage III, has been anchored with an open aperture centered on the beam line. The blade apertures are nuch larger than the diameter of the collimated beam. In the vacuum system, the mean free path of gas is always much greater than the local geometry. In the sample region, the pumping speed is calculated to be at least $15001 / \mathrm{s}$. This pump conductance has been confirmed by pressure measurements at known gas loads. Although the vaporization time scale is too short for the pressure gauges to respond, the local pressure outside the gas-dynamic shock boundaries should be in the molecular flow regime, with a mean free path length much greater than the distance from sample to the skimmer orifice. Thus we can eliminate. from consideration any possible perturbation of the plume sample by postexpansion coliisions.

The sample was mounted on a stainless steel bar. Graphite samples were taken from a rod of spectroscopic grade graphite selected by the NBS Analytical Chemistry Division for spectrographic analyses on the basis of its freedom from contaminants. The hydrogen content is unknown but probably insignificant, al though weak mass spectrometric signals were observed corresponding to $\mathrm{C}_{2} \mathrm{H}_{2}$ and other low hydrogen-content gas species. Possible hydrocarbon contributions to the $C_{n}{ }^{+}(n=1-5)$ ion signals are estimated to be less than a few percent and can be neglected. Sample preparation consisted of parting-off a short section of $1 / 4$ inch $(-6.4 \mathrm{~mm})$ rod, and milling a flat of the desired angle using carefully cleaned steel cutting tools. The angle between sample surface and mount (or laser beam, see figure 1) was chosen as 15 degrees for the data reported here. This geometry represented a compromise between the laser-entrance and mass spectrometer sampling angles. 
The reduced mass fiux for the slightly off-axis sampling was not expected to be siznificant, as shown by the earlier study of Covington et al., [1977]. Erom post-run examination of deposit patterns around vacuum chamber apertures, the vaporization process was shown to be approximately independent of the laser incidence angle and the olume was normal to the surface to within a few ( - \pm 5 ) degrees for sample-surface to mount angles from 45 to 15 degrees.

In a typical laser-induced vaporization experiment, a $7 \mathrm{nsec} 10 \mathrm{~mJ}$ laser pulse was focused at the sample surface by a $500 \mathrm{~mm}$ focal length $\mathrm{f} / 10$ lens which produced a spot size of $250 \mathrm{microns}$. The $20 \mathrm{~J} / \mathrm{cm}^{2}$ of deposited energy is converted into thermal excitation at the surface and penetrates to a depth of only a few tens of atomic diameters. Rapid vaporization occurs, leading at peak-temperature to the formation of a gas-dynamically stabilized plume which yields a molecular beam. The beam is collimated by three circular differentially pumped apertures, and travels a distance of $26 \mathrm{~cm}$ between the sample and ion chamber. Each aperture is sized to just allow clear passage of the beam through the $4.8 \mathrm{~mm}$ diameter entrance aperture of the mass filter ion source, and also through the larger ion source exit. Species are ionized by electron impact at adjustable voltages, and mass analyzed by a quadrupole mass filter. These filtered ions are then collected and amplified by an electron multiplier. The signals are averaged, with 0.5 usec/channel dwell time, with the sweep synchronized by a trigger generated from the onset of each laser pulse. This data collection process gives a timeresolved intensity-profile of an individual mass peak. Sufficient signal time-sweeps are collected (typically between 100 and 1000) to provide reasonably good statistics in the leading edge and peak centroid area. The process is repeated for each individual mass peak. It was observed that, 
dependent on laser beam to suriace angle, the initial signal intensity would decay during the first few tens of pulses and then stabilize at a value about half that produced by the initial pulse. For this reason, each series of intensity-time profiles (for individual masses) were collected after a ore-conditioning period, and successive series were taken from a new spot on the surface. To check the amount of signal loss, with the number of laser shots, the major peak $\left(C_{3}\right)$ was sampled both at the beginning and end of a series.

\subsection{Results:}

Eigures 3-5 show time-resolved, averaged intensity-profiles for the 36 $\left(\mathrm{C}_{3}{ }^{+}\right), 12\left(\mathrm{C}_{1}{ }^{+}\right)$, and $24\left(\mathrm{C}_{2}{ }^{+}\right)$amu ions, respectively. Similar data were collected for the ions $\mathrm{C}_{4}{ }^{+}$and $\mathrm{C}_{5}{ }^{+}$. As has been noted in previous studies, curing initial heating hydrocarbon impurities are released from even high purity graphite (e.g., see Zavitsanos and Carlson, [1973]). In the present study, this effect was observed primarily in the form of $\mathrm{C}_{2} \mathrm{H}^{+}(25$ amu $), \mathrm{C}_{2} \mathrm{H}_{2}{ }^{+}$ (26 amu), and $\mathrm{C}_{4} \mathrm{H}_{2}{ }^{+}$(50 amu) mass spectral ions during the initial first few Iaser shots onto a given surface position. These signals tended to vanish more rapidly than those for the $c_{n}$ species, suggesting the presence of surface hydrocarbon contamination. of particular note was the long time delay for the 26 amu $\left(\mathrm{C}_{2} \mathrm{H}_{2}\right)$ species, as compared with the $\mathrm{C}_{\mathrm{n}}$ ions. A similar effect may be noted in the results of Lincoln [1969]. For comparison, both our data and Lincoln's show a time difference between 26 and 36 amu of 150 to $200 \mathrm{~m} \mathrm{sec}$. We attribute this time delay either to the $\mathrm{C}_{2} \mathrm{H}_{2}{ }^{+}$arising from electron impact fragmentation of a heavier polyacetylene precursor (the delay implies a species of $110 \pm 15$ amu) or, to a reaction time such as diffusion in the substrate. The 57 amu $\left(\mathrm{C}_{4} \mathrm{H}_{9}{ }^{+}\right)$ion showed an even larger delay time and the intensity-time profile was exeptionally wide. 
The intensity-time propiles from $C_{n}$ are quite similar to those observed

in analogous measurements by Oistad and Olander [1975] for Fen species.

These authors provide a theoretical analysis of the atom density pulses in

terms of an equilibrium vaporization model with known laser pulse energy-time profizes. A similar anazysis should be possible for the $C_{n}$ system.

Table 1 gives resuits from two runs at widely differing ionizing electron energy. The validity of the assignment of ions to neutral precursors is borne out by the insignificant changes in ion ratios from 26 eV to $96 \mathrm{eV}$ ionizing electron energy. Ion intensities, proportional to neutral gas concentrations, were computed from the intensity-time profiles using, (1) the peak maximum at peak centroid, and (2) the integrated peak intensity. Both approaches gave consistant results which were almost independent of ionizing energy. However, the peak maximum results indicated the presence either of a slight excess of atomic-carbon, or of an unknown sampling artifact which affects only the lowest mass $C_{n}$ species (see also Section 2.3).

The results of Table 1 may be interpreted to indicate that the graphite species vaporization coefficients appear to be very close to unity, contrary to the results of earlier work. This observation may result from the effect of signal-averaging several hundred vaporization events from a crater which could serve as a crude Knudsen cell. Other significant causes of data differences between this and earlier work may arise from our avoidance of a significant laser/plume interaction and the use of very short laser pulses to reduce perturbation of the gas-dynamic process. Also, as the present study was performed of the central plume axis, it is possible that if 
non-equilibrium effects occurred only along the perpendicular axis they would not have deen observed in the present work. As the plume is highly forwardpeaked in the perpendicular direction this possibility needs further study.

\subsection{Temperature Determination}

For these initial studies, several indirect methods have been used to derive an estimate of the temperature $\left(T_{0}\right)$ of the laser heated spot. Application of potentially more accurate optical pyrometric methods have been deferred due to uncertain emissivity data and the difficulty of accounting for plume contributions to the emission signals. Under the laser pulse conditions used, it is likely that only the surface layer (a few wavelengths, i.e., - 2000 to $5000 \mathrm{~nm}$ ) is heated and the total extent of vaporization is confined to an area nearly equal to that of the laser spot [Hal1, 1984]. The initial tests used a laser spot intensity profile which is roughly "donutshaped." The effect of such a spot geonetry, relative to a gausian profile, should be to level-out the temperature profile of the heated area.

\subsubsection{Beam Velocity Analysis}

The time-of-arrival, $\Delta t$, of the beam-species may be used to obtain the plume temperature. Regardess of the exact model of the vaporization and bean-forming process, if a collection of gas molecules are in thermal equilibrium their velocity function is proportional to $\left(T_{0} / M\right)^{i / 2}$, where $M$ is the individual species molecular weight. As $\Delta t$ is inversely proportional to velocity, a linear plot of $\Delta t$ versus $(M)^{1 / 2}$ is indicative of thermal equilibrium. Figure 6 shows that the various $c_{n}$ species exhibit such behavior, although the slope appears to be slightly dependent on electron energy, for reasons yet to be determined. Using the assumption of the equipartition of translational energy, one has 


$$
M v^{2} / 2=3 k T / 2
$$

where $v$ is the most probabie velocity, i.e., the peak of the thermal velocity distribution, and $T$ is the beam temperature $\left(\left\langle T_{0}\right)\right.$. Because the peak of the observed ion intensity-time-profile is considered to be caused by cooling of the sample, the arrival times were selected at the half-height position of the leading edge of the profile. Correlating this time with the most probable velocity yields the time-of-arrival function

$$
\Delta t=(d / 3 k T)^{1 / 2} \cdot M^{1 / 2}
$$

where $d$ is the flight distance, $26 \mathrm{~cm}$. Note, in figure 6 , that the zero mass intercept, a measure of the inherent delay in the quadrupole filter, is quite small. From these arguments, and the slope of the $100 \mathrm{eV}$ curve of figure 6 , we obtain a beam temperature estimate of $2500 \pm 300 \mathrm{~K}$. This temperature is much lower than is reasonable for the degree of vaporization observed and may be taken as evidence of expansion-cooling, followed by translational equilibration as the vapor species pass through a shock-front stagnation zone. Onse, et al., [1979] have noted that for free vaporization from a surface, gas-dynamic models predict a rapid temperature drop to the sonic point such that $\mathrm{T}-2 \mathrm{~T}_{0} / 3$. This prediction, together with the above velocity model, suggests a pre-expansion temperature $\left(-T_{0}\right)$ of $3800 \pm 300 \mathrm{~K}$, which is quite consistent with the thermodynamic arguments given below. Although this temperature analysis is not yet rigorous, our experimental results (not given here) for the thermochemically more-established BN system provide excellent 
confirmation, as we obtain $4000 \pm 300 K$ by comparing the $\sigma_{2}+$ arrival time relative to that for $3^{+}$at $I_{0}=2900 \mathrm{~K}$ (see table 2 ). Other supporting arguments are also summarized in table 2 .

\subsubsection{Species Intensity Analysis}

The time-of-arrival evidence for themal aquilibrium sugjasts that the

"known" $C_{n}$ species distribution with temperature can be used to derive the sample temperature $\left(T_{0}\right)$ fron the measured species concentration ratios. Also, the beam-formation process is quite similar to that for more usual supersonic expansions, where the beam composition represents a "frozen equilibrium" and corresponds to the pre-expansion temperature/pressure conditions [BonnelI and Hastie, 1979]. The high pumping speed of the vacuum system used for the present studies, and the pulsed nature of the gas evolution process, further ensures high expansion ratios and "frozen equilibrium" compositions in the gas-dynamic process.

Values of "known" $C_{n}$ species concentration ratios were calculated as a function of temperature using the JANAF [1971] thermochemical tables. While other sources of thermodynamic data exist (see discussion in section 2.4), these tables still provide the most widely accepted critically evaluated thernodynamic functions for $C_{n}$ species. Table 1 gives temperatures calculated from the 1 isted $C_{n} / C_{3}$ ratio data. Note that al though the temperature from the $C_{1} / C_{3}$ ratio fortuitously agrees with the post-expansion temperature (time-of-arrival data), such a temperature is unrealistically low for the observed species pressures. The corresponding ratios for the $C_{4}$ and $C_{5}$ species yield temperatures that are more consistent with those expected and also with those indicated by the above beam velocity analysis. 
The anomalous low temperature result could be interpreted as being due to an apparent excess of $C_{1}$. Arguments for and against additional sources of $\mathrm{C}_{1}{ }^{+}$include:

- Electron impact fragmentation of higher mass $C_{n}$ species or contaminants such as CO or hydrocarbons. In this connection, it should be noted that the literature data were usually obtained at lower electron energies than for the present study. However, the present results are consistent with the lower eV data of Berkowitz and Chupka [1964] and Drowart, et al., [1959].

- A compelling argument against significant fragmentation in the present study is the time-of-arrival result which indicates that $c_{1}{ }^{+}$arises primarily from a 12 amu neutral, i.e., $C_{1}$.

- Analysis of the $\mathrm{C}_{\mathrm{n}}{ }^{+}$ion-stabilities (bond dissociation energies) indicates no loss of stability on ionization of $\mathrm{C}_{n}$; hence no major fragmentation effect is likely.

- The constancy of ion-ratios over the range 26 to $96 \mathrm{eV}$ is consistent with an absence of fragmentation and the existence of a single ion-precursor for all ions.

- The $\mathrm{C}_{1}{ }^{+}$appearance potential curve indicates $\mathrm{C}_{1}$ as the major precursor.

- From the $\mathrm{C}_{1}{ }^{+}$ion intensity, the carbon-atom pressure $\left(\mathrm{P}_{C}\right)$ is calculated to be equal that obtained from JANAF [1971]. For this calculation $\mathrm{k}_{C}$, the mass spectrometer ion intensity-partial pressure proportionality constant, was obtained from our established boron ion intensity data (not given here). 
Wachi and Gilmartin [1970] found that $C_{1} / C_{n}$ decreased with time, and also depended on the sample preparation and surface morphology. Also, considerable literature controversy exists concerning the entropy and hence absolute partial pressure of $C_{3}$. Thus, the use of observed $c_{1} / C_{3}$ ratios together with JANAF [1971] calculated ratios to inper temperatures, etc., seems risky. In this connection, Iiterature more recent than JANAF [1971], as reviewed by Meyer and Lynch [1973], indicates $C_{1} / C_{3}<J A N A F$, with $C_{3}$ being more significant than JANAF; e.g., at $4000 \mathrm{~K}$, with pressures indicated in atm,

$$
\begin{aligned}
& C_{1} / C_{3}(\text { JANAF })=\left(7.9 \times 10^{-2}\right) /\left(5.0 \times 10^{-1}\right)=0.16 \text {, whereas } \\
& C_{1} / C_{3}(M \& L)=\left(7.9 \times 10^{-2}\right) /(1.2)=0.066 \\
& \text { i.e., JANAF is higher by a factor of } 0.16 / 0.066=2.4 \text {, } \\
& \text { i.e., } C_{3}(M \& L)=2.4 \times \text { JANAF. }
\end{aligned}
$$

This difference is comparable with the uncertainty in cross sections used to translate ion intensity to partial pressure data. However, use of the Meyer and Lynch [1973] or Meyer, et al., [1973] data and our $C_{1} / C_{3}$ results gives an even lower $T_{0}$ than the JANAE value of $2600 \mathrm{~K}$, which is impossible. Hence the $\mathrm{C}_{1}{ }^{+}$data do not appear to have thermodynamic significance for $\mathrm{C}_{1}$ concentration measurement.

Another, less-likely, argument as to why $C_{1} / C_{3}$ gives a lower $T_{0}$ than $C_{n} / C_{3}(n>1)$ is based on the higher sublimation enthalpies for $C_{n}(n>1)$, as compared with $C_{1}$. This means that $C_{1}$ becomes a relatively more important species at lower temperatures and, as the hot spot cools, $C_{1}$ could become more significant than $C_{n}(n>1)$. However, this would require $T_{0}$, as calculated from the crater size, to be less than from the $C_{n} / C_{3}$ ratio data. 
No systematic crater size data have been obtained to test this hypothesis. However, for our analogous study of $B N$ (results not given here), the crater size measurements gave a high value for $T_{0}$. This explanation would also require our observation of $B / B_{2}$ to yield a lower $T_{0}$ which was not the case. For the case of the $C_{2} / C_{3}$ ratio (see table 1), if the relative ionization cross-sections were $1 / 1.5$, which is quite reasonable based on empirical trends in other systems, the calculated temperature would be 4200 $K$, in agreement with the values obtained using the $C_{4}$ and $C_{5}$ species. This cross-section ratio agrees favorably with the estimate of $1 / 1.23$ given by Meyer and Lynch [1973]. The higher polymeric $C_{n}$ species should have crosssection ratios close to unity, which we have assumed in the present analysis.

\subsection{Literature Studies of Laser-Induced Vaporization of Craphite \\ Since the JANAF evaluation, dated December, 1969 [in JANAF, 1971], a} number of studies of the graphite vaporization system have been reported over the period 1968 to 1983. Analysis of the results of these studies indicates that the equilibrium distribution of various carbon species at temperatures greater than $2800 \mathrm{~K}$ is still uncertain.

\subsubsection{Literature Survey for the Period 1968-1983}

\section{- Zavitsanos [1968]}

Zavitsanos [1968] carried out laser vaporization mass spectrometric studies using conditions similar to those of the present work. However, only the $C_{1} / C_{3}$ ion intensity ratios are comparable between the two studies, as shown in table 3. The crater dimensions observed by Zavitsanos [1968], and those found in the present study, are notably similar for various graphitetypes at $4100 \mathrm{~K}$ with similar laser energy conditions. 
- Clarke and Eox [1969]

The vaporization data from graphite filaments at temperatures to $3400 \mathrm{~K}$ were analyzed in terms of $\mathrm{C}_{2}$ as the principal species with a vaporization coefficient, $x=1$. For this analysis, the JANAF $\Delta H_{r n}(298)$ (i.e., for $2 C(s)=C_{2}$ ) was assumed to be correct and equai to $332.6 \mathrm{~kJ} / \mathrm{mol}$. Assumptions of $C_{1}, C_{2}$, ard $C_{3}$ as the principal species with $x=1$, or with the Thorn and Winslow [1957] a values, do not fit the data. Later workers have apparently not attempted to rationalize the results of Clarke and Eox [1969] with the prevailing viewpoint (including the present results) of $C_{3}$, rather than $C_{2}$, as the dominant species. These authors also cite all pertinent earlier literature work.

Wachi and Gilmartin [1970]

These workers studied the free vaporization (Langmuir) behavior of various graphites using both double-focusing magnetic sector and timeof-flight mass spectrometric detection of the $C_{1}$ to $C_{5}$ species. A relatively low ionizing electron energy of $17 \mathrm{eV}$ was used. Above $17.5 \mathrm{eV}$, the appearance potential curve for $\mathrm{C}_{3}$ showed a pronounced upward curvature, indicating possible fragmentation of higher molecular weight species. Ion molecule reactions in the ion source were also suggested as a possible additional source of $\mathrm{C}_{3}{ }^{+}$. Apparent activation energies were basically in agreement with those reported eariler by Zavitsanos [1968]. No attempt to convert the ion intensity data to absolute species concentrations was made in this study. Thus, these regults cast little light on the equilibrium thermodynamic vaporization behavior of the various $C_{n}$ species. It is pertinent, however, to note the close similarity between the activation energies and equilibrium enthalpies (1iterature data) of vaporization. This similarity suggests local equilibrium conditions may be present under free 
vaporization conditions for graphite. Another important observation from this study was the pronounced time-dependency of the relative ion intensities, with $\mathrm{C}_{3}{ }^{+}$showing a strong increase, with time, relative to $\mathrm{C}_{1}{ }^{+}$and $\mathrm{C}_{2}{ }^{+}$. This effect was tentatively attributed to changes in surface morphology and the suzgested possible formation of an allotropic form of carbon.

o ililne et al. [1972]

Using Knudsen effusion mass spectrometry, these workers obtained relative ion intensity mass spectral data for $\mathrm{C}_{1}{ }^{+}-\mathrm{C}_{7}{ }^{+}$at temperatures to $3300 \mathrm{~K}$ at $17 \mathrm{eV}$ electron energy. The ion ratios between $c_{1}, c_{2}, c_{3}$ and $C_{5}$ agree well with the extrapolated data of Drowart et al. [1959], and hence JANAF [1971]. The $c_{4}$ partial pressures were lower than those indicated by JANAF [1971] and the $C_{6}$ and $C_{7}$ values were lower than theoretical predictions, including those of Leider et al., [1973]. Useful second law data were obtained only for the relatively abundant $C_{3}$ and $c_{1}$ species. During initial heating, $\mathrm{C}_{4}(48 \mathrm{amu})$ was anomalously high due to presence of a $\mathrm{Ti}$ impurity at the same amu. A comparison between the extrapolated results of Milne et al., [1972] and the present work is given in Table 4. Note that $C_{2} / C_{3}$ is the only ion ratio in agreement for the two studies.

The Milne et al., [1972] intensity-time profiles showed multiple peaks from each ion, which they attributed to possible ion trapping in the ion source. The positions and shapes for $\mathrm{C}_{1}{ }^{+}, \mathrm{C}_{2}{ }^{+}$and $\mathrm{C}_{3}{ }^{+}$suggested substantial $C_{3}$ fragmentation at $50 \mathrm{eV}$ and none at $17 \mathrm{eV}$. There was also some indication of $\mathrm{C}_{3}{ }^{+}$fragment-ion formation at the higher temperatures. The narrow $\mathrm{C}_{3}{ }^{+}$ peak shape was indicative of non-effusive expansion conditions. Note, however, that their pressures did not exceed $-10^{-3}$ atm for a $1 / 8$ in. diameter cell orifice size and these conditions, while outside of molecular effusion, would not lead to significant gas-dynamic cooling. 


\section{- Zavitsanos and Carison [1973]}

Knudsen effusion mass spectrometry to $3000 \mathrm{~K}$ indicated good agreement with the JANAF [1971] $C_{1}-C_{4}$ partial pressures. But the JANAF $C_{1}$ pressures were used to calibrate the pressure scale. These workers also used the newer $\mathrm{C}_{3}$ thermodynanic functions of Strauss and Thiele [1967] but this did not improve the poor agreement between second and third law $\mathrm{C}_{3}$ vaporization enthalpies. The possibility (also suggested by others) of a temperaturedependent $C_{3}$ ionization cross section was mentioned as a possible source of error with the second law enthalpy. Heavier species than $C_{4}$ were not significant in this study. This observation does not conflict with the analysis of Leider, et al., [1973] since they predict $C_{5}-C_{7}$ as significant species at higher temperatures ( $>4000 \mathrm{~K}$ ) than the $<3000 \mathrm{~K}$ achieved by Zavitsanos and Carlson [1973]. The appearance potential data of these latter authors was considered evidence of negligible fragmentation at ionizing electron energies to $20 \mathrm{eV}$. However, the structure of their curves could also be interpreted to indicate fragmentation. More precise appearance potential measurements of $C_{3}$ [Wachi and Gilmartin, 1970] over pyrolytic graphite at $2788 \mathrm{~K}$, showed a pronounced break at $17.5 \mathrm{eV}$, indicative (but not proof) of fragmentation of a higher polymer or other carbon-containing species. Extrapolation of these data to $26 \mathrm{eV}$ suggests about 30 percent of $\mathrm{C}_{3}{ }^{+}$could arise from fragmentation in the present studies.

\section{- Meyer et al.s [1973]}

Pulse laser vaporization of pyrolytic graphite with mass spectrometric (time-of-flight) analysis indicated $C_{n}$ integrated ion intensities (relative) of: $C_{1}(1.0), C_{2}(1.3)$, and $C_{3}(18)$, at $18.6 \mathrm{eV}$, with higher n-species being negligible. Note that our corresponding values are: $c_{1}(1.0), c_{2}(0.35)$, and $\mathrm{C}_{3}(3.1)$, at $26 \mathrm{eV}$. Using estimated ionization cross sections and other 
ion intensity conversion factors, the corresponding relative partial pressures for the Meyer et al., [1973] data are: $C_{1}(1.0), C_{2}(0.32)$, and $C_{3}$ (35). Based on the Palmer and Shelef [1968] $C_{3} / C_{1}$ pressure ratio data, the temperature is indicated as $4500 \mathrm{~K}$. Pulsed laser vaporization studies of graphite generally indicate surface temperatures in the range 4000 to $4500 \mathrm{~K}$. From their analogous studies on $I a C$, where only $C_{1}$ and $C_{3}$ were significant, we can argue that the fragmentation, $\mathrm{C}_{1}{ }^{+}\left(\mathrm{C}_{3}\right)$ or $\mathrm{C}_{2}{ }^{+}\left(\mathrm{C}_{3}\right)$ is not a significant factor in the graphite mass spectra, at least to $18.6 \mathrm{eV}$.

Note that a significant difference between the Meyer et al., [1973] experiments and ours is their use of a single laser pulse and hence the need to consider vaporization coefficients in their conversion of ion intensities to partial pressures. Their intensity-time results are similar to ours and do not show the anomalous secondary peaks characteristic of the Milne et al., [1972] observations. However, their laser-plume geometry was coaxial, giving rise to possible laser perturbation of the plume species.

Hydrocarbon species noted by Meyer et al., [1973] over pyrolytic graphite included, $\mathrm{C}_{2} \mathrm{H}_{2}, \mathrm{C}_{4} \mathrm{H}_{2}$, and $\mathrm{C}_{6} \mathrm{H}_{2}$, in addition to $\mathrm{H}_{2}$ and $\mathrm{CO} ; \mathrm{C}_{2} \mathrm{H}_{2}$ and CO were also noted over TaC.

- Meyer and Lynch [1973]

Their analysis of literature results is closer to that of Palmer and Shelef [1968], and also of Zavitsanos [1968] and Leider et al., [1973] than that of JANAF [1971]. The main result is that the $C_{3}$ partial pressures are predicted to be about three times greater than for the JANAF [1971] data. At temperatures in the region of $4000 \mathrm{~K}$, the following differences are found between the Meyer and Lynch [1973] and JANAF [1971] evaluations: 


$\begin{array}{ll}\frac{C_{1} / C_{3}(\mathrm{ML})}{C_{1} / C_{3}(\text { JANAF })}=0.309 & \frac{C_{2} / C_{3}(\mathrm{ML})}{C_{2} / C_{3}(\text { JANAF })}=1.06 \\ \frac{C_{4} / C_{3}(\mathrm{ML})}{C_{4} / C_{3}(\text { JANAF })}=2.54 & \frac{C_{5} / C_{3}(\mathrm{ML})}{C_{5} / C_{3}(\text { JANAF })}=2.35 .\end{array}$

Table 5 gives a comparison of temperatures calculated using the ion intensities of the present work together with the Meyer and Lynch [1973] and JANAF [1971] partial pressure ratios. Note that the comparison using the JANAE data gives the more realistic temperatures.

- Lundell and Dickey [1977]

The graphite rate-of-mass-loss data of Lundell and Dickey [1977] agree well with JANAF [1971] provided unit vaporization coefficients are assumed for the temperature range of $4000-4500 \mathrm{~K}$. Under the $\mathrm{CW}-\mathrm{CO}_{2}$ laser heating conditions used, the vapor plume was supersonic. Temperatures were determined by pyrometry of the surface using an estimated emissivity. This is one of the few graphite vaporization studies where controllable CW laser radiation was used and direct surface temperature measurements were made.

- Covington et al., [1977]

These workers have analyzed the gas-dynamic behavior of free-jet expansions from laser-vaporized carbon surfaces at temperatures to $4500 \mathrm{~K}$. Their results are consistent with the JANAF [1971] tables, indicating equilibrium conditions and a species-averaged vaporization coefficient of 0.9 and an emissivity of 0.9 . The data agreement with JANAF [1971] assumes $\mathrm{C}_{1}$, $C_{2}$ and $C_{3}$ as the major species with the latter predominant. These workers also concluded that the vaporization process was independent of microscopic surface roughness. 


\section{- Gupta and Gingerich [1979]}

These workers report Knudsen effusion data for $C_{1}, C_{2}$, and $C_{3}$ at temperatures to $2700 \mathrm{~K}$. For the third law enthalpies, fair agreement with JANAF [1971] was obtained for $C_{1}$ and $C_{2} ;$ for $C_{3}, \Delta H_{a t o m ~}(298)=1313 \pm 6.6$ $\mathrm{kJ} / \mathrm{mol}$, as compared with the JANAF [1971] value of $1321 \pm 21 \mathrm{~kJ} / \mathrm{mol}$.

\section{- wulison et al. [1980]}

These workers determined a maximum laser plume temperature of $3600 \pm 300 \mathrm{k}$ from the $\mathrm{CN}-\mathrm{impurity}$ vibrational temperature for a pulsed laser graphite vapor plume. We believe that the conditions used would have yielded a total carbon-species pressure of about an atmosphere, similar to the present work.

\section{- Lunde1I [1982]}

From a review of earlier work, Lundell [1982] concluded that at relatively low temperatures ( 1400 to $2400 \mathrm{~K}$ ) the vaporization coefficients are not well known but are considerably less than unity and differ between the various $C_{n}$ species. At higher temperatures (3500 to $4500 \mathrm{~K}$ ), the vaporization coefficients approach unity. Note that for the best available vaporization coefficient estimates and the JANAF [1971] data, $C_{1}$ is predicted to be the predominant species at the lower temperature range and $C_{3}$ at the higher range, with $\mathrm{C}_{7}$ or other higher molecular weight species becoming significant above the boiling point.

- Baker et al., [1983]

The recent work of Baker et al., [1983], using similar methodology as for the study of Covington et al., [1977], provides an alternative analysis to that of Lundell [1982]. The results differed significantly from JANAF [1971] and were more consistent with the re-evaluation of Leider, et al., [1973]. However, the analysis depends to some extent on assumed emissivity, 
species distribution, and vaporization coefficient behavior. Their analysis indicates an average $\alpha=0.4-0.7$, based on JANAF [1971], but that extrapolating to the melting point would require $\propto>1$, which is the primary basis for disagreement with JANAF. However, the linearity of the temperature-pressure extrapolation process is by no means assured. Comparison with the Livermore thermochemical tables [Leider, et al., 1973] indicates $\alpha=0.2-0.6$ over the data range and -0.8 at the melting point. Based on the physical reasonableness of a approaching unity at the melting point, these authors preferred the Livermore to the JANAF analysis. The differences in Livermore and JANAF pressures are primarily only significant at temperatures higher than about $4200 \mathrm{~K}$, which is the region most dependent on extrapolations and spectroscopically-based thermodynamic functions. The results of Baker et al., [1983] suggest a to be strongly temperature dependent. In this connection, it is pertinent to note that their carbon surface morphologies were relatively flat, as opposed to the cratered condition produced in the present studies.

\subsubsection{Literature Summary, for the Period 1968-1983}

Clarke and Fox [1969]

- Indirect evidence of $\mathrm{C}_{2}$ as the major species and $\alpha=1(3400 \mathrm{~K})$. Wachi and Gilmart in [1970]

- Relative intensities of $\mathrm{C}_{n}{ }^{+}(\mathrm{n}=1$ to 5$)$ strongly dependent on time and sample form.

- Possible evidence for $\mathrm{C}_{3}{ }^{+}$fragment ion formation or ion-molecule reactions in the ion source above $17.6 \mathrm{eV}$.

- Data insufficient to compare with JANAF [1971].

Milne et al., [1972]

- Basically in agreement with JANAF [1971] (to $3300 \mathrm{~K}$ ).

- Time-of-arrival data suggests some fragmentation of $C_{3}$. 
Meyer et al.. [1973]

- $C_{3} / C_{1}$ ion ratios are consistent with a laser plune temperature of $4500 \mathrm{~K}$.

- No evidence of $\mathrm{C}_{1}{ }^{+}$or $\mathrm{C}_{2}{ }^{+}$fragment ions from $\mathrm{C}_{3}$ at $18.6 \mathrm{eV}$. Meyer and Lynch [1973]

- $\mathrm{P}_{3}-3 \mathrm{X}$ JANAF $[1971]$

\section{Zavitsanos and Carlson [1973]}

- Knudsen mass spectrometry results to $3000 \mathrm{~K}$, agree with JANAF [1971]. Lundell and Dickey [1977]

o Results agree with JANAF [1971] at $T=4000-4500 \mathrm{~K}$.

- Conditions similar to the present study but mass-loss method used instead of mass spectrometry.

Covington et al., [1977]

o. Laser vapor-plume analysis to $4500 \mathrm{~K}$.

$0 \propto-0.9$.

- $\mathrm{C}_{3}$ is indirectly indicated the major species.

- Results are consistent with JANAF [1971].

Wulfson et al., [1980]

- Laser vapor-plume temperature $3600 \pm 300 \mathrm{~K}$.

Baker et al., [1983]

- Data more consistent with analysis of Leider et al., [1973] than for JANAF [1971].

$0 \propto=0.2-0.6 ;-1$ at melting point

o a strongly temperature dependent.

o Data depart from JANAF [1971] mainly at $T>4200 \mathrm{~K}$.

o P total $\leq 2 \times$ JANAF up to $4200 \mathrm{~K},-3 \mathrm{X}$ [JANAF] at $4500 \mathrm{~K}$. 
2.4.3 Literature Summary, for the Pre-1968 Pericd

The JANAF [1971] evaluation is based on data available orior to 1968. An independent critical analysis or results from this period has also been made by Palmer and Shelef [1968]: using theoretical $C_{3}$ entropy results not available to JiNis [i971].

The principal conclusions are:

- P total - $10 \times$ PJANAF (at T - $4000 \mathrm{~K}$ ).

- Tboiling - $3850 \mathrm{~K}$ vs. $4150 \mathrm{~K}$ for JANAF [1971].

- The carbon-atom may be used as a reference point as its properties are well established.

- Entropy of $\mathrm{C}_{3}$ is about $21 \mathrm{~J} / \mathrm{mol} \cdot \mathrm{K}$ greater than JANAF at [1971] $4000 \mathrm{~K}$. 2.4.4 Conclusions From the Literature Survey

Despite recent suggestions to the contrary, the JANAF [1971] tables still appear to be the most consistent with the available data. However, a re-evaluation of all the thermodynamic functions is warranted as the JANAF [1971] data-consistency may result from offsetting errors, particularly for the $\mathrm{C}_{3}$ species.

\subsection{Carbon Vaporization from Carbides}

For spacecraft survivability, under laser irradiation, the development of ablative coatings is a promising approach. An important coating requirement is the maximization of energy absorption, which implies minimizing the energy stored as chemical bonds in the vaporized protectant. In the case of carbon, the fact that $C_{3}$ is the predominant vapor species at high temperatures makes carbon a less favorable ablator than if carbon atoms were the preferred vaporizing species. Over pure carbon, it is thermodynamically unreasonable to significantly modify the vapor species distribution. However, with refractory metal carbides, the reduced thermodynamic activity of carbon species should favor release of lower molecular weight $\mathrm{C}_{n}$-species, 
in comparison with graphite. Carbides can also improve the refractory properties of ablative coatings. Tantalum carbide ( $\mathrm{T} a \mathrm{C}$ ) is a promising abiation material and is a suitable test case for a detailed analysis of vaporization kinetics. A limited understanding of TaC vaporization processes is available from several earlier studies, described as follows.

Langmuir vaporization studies of refractory metal carbides, including those of $\mathrm{Ta}$, $\mathrm{Nb}$, Hf, $\mathrm{Zr}$, and $\mathrm{Ti}$ have been reported by Fesenko and Bolgar [1969]. Vaporization rates increased in the above order, Ta to Ti. The data were also consistent with vaporization to metal plus atomic-carbon. However, this assignment may not be definitive owing to the non-molecular-specific approach used. At the highest temperature of $3373 \mathrm{~K}$, the total pressure over the congruent vaporizing composition, $\mathrm{TaC}_{0.71}$, was $4.5 \times 10^{-5} \mathrm{~atm}$. Erom this pressure, and the condition of congruency, we can compute the thermodynamic activity of $\mathrm{C}_{3}$ as $1.56 \times 10^{-3}$. This reduced activity of $\mathrm{C}_{3}$ in $\mathrm{TaC}_{0.71}$, as compared with graphite ( 1.0 by definition), favors dissociation to $C_{1}$. At $3373 \mathrm{~K}$ the ratio $\mathrm{P}_{\mathrm{C}_{1}} / \mathrm{P}_{\mathrm{C}_{3}}-10$, whereas for graphite the ratio is $0.17,1 . e .$, the atomic-carbon-enhancement factor is 58.8 for the carbide.

More recent vaporization studies of TaC using laser vaporization mass spectrometry (at $18.6 \mathrm{eV}$ ) indicate $C_{3}$ as the predominant species [Meyer et al., 1973]. However, the substrate conposition is unspecified in these studies and could well be closen to $\mathrm{TaC}$ than $\mathrm{TaC}_{0.71}$. This situation would tend to favor a higher $C_{3} / C_{1}$ ratio than for the work of Fesenko and Bolgar [1969]. Using the measured relative partial pressures of $C_{3} / C_{1}$, in comparison with values calculated from the Palmer and Shelef [1968] evaluation for graphite, a surface temperature of $4500 \mathrm{~K}$ was indicated. The JANAF [1971] derived temperatures would be greater, but vaporization coefficient and 
Lonization cross section uncertainties probably contribute to this difference. A comparison or tne observed $\mathrm{TaC}$ and $\mathrm{C}$ vapor species abundances (integrated ion intensities) indicates $C_{1}: C_{2}: C_{3}$ values of $1.0: 0.06: 2.2$ and $1.0: 0.32: 35$, respectively, and presumably at $4500 \mathrm{~K}$ in both cases. These observations do not necessarily conflict with the lower temperature studies of Fesenko and Bolgar [1969] owing to the large temperature differences together with the strong $C_{3} / C_{1}$ temperature dependence. Meyer et al., [1973] argue that the carbide vapor composition may reflect the molecular structure of the solid phase and that different carbides may produce different $C_{n}$ distributions. A higher laser energy (18 J of focused energy versus $0.1 \mathrm{~J}$ for graphite) was needed for $\mathrm{TaC}$ due to its greater reflectivity. The results could not be quantified because of the non-congruent vaporization. Also, no direct indication of the TaC temperature was obtained in these experiments, but the signals were approximately an order of magnitude weaker than for graphite.

In view of the incomplete and disparate nature of the literature studies, further examination of the molecular composition in laser plumes over tantalum carbide samples is needed and planned.

\section{Subtask B: Cluster Formation Studies}

Laser vaporization processes can result in relatively high pressures of vapor species, as shown by the results for $C_{n}$ given in Section 2 . When a high pressure vapor expands adiabatically into a vacuum environment the temperature can fall markedly, leading to a supersaturated vapor state. Such a condition tends to favor homogeneous nucleation, with the formation of cluster intermediate, aerosol, and particulate states. While the laser vaporization studies of graphite, described in Section 2, showed evidence of expansion-cooling there was no indication of cluster formation. Independent 
control of the source pressure and temperature, which was not possible with the graphite studies, is required to understand the mechanistic details of the vapor to cluster to aerosol transformation. For this purpose, we have developed a chamber in which the total pressure and temperature can be independently controlled, and from which expansions into a vacuum chamber can be monicored with mass spectrometric detection [Bonnell and Hastie, 1979 ]. Alkali halides have been selected as test cases for monitoring cluster formation processes.

The apparatus, termed Transpiration Mass Spectrometer (TMS), consists of an initial chamber for vapor transpiration and molecular beam production, and a second chamber where modulation of the molecular beam and mass analysis are performed. Figure 7 shows the transpiration inlet system, located in a vacuum chamber. The entire system is heated by a tantalum foil furnace (not shown), and the beam is directed to a quadrupole mass spectrometer which is operated in a cross-beam configuration. The unit is laser aligned with the beam axis directed toward the ion source. Differentially pumped apertures collimate the beam and a mechanical chopper modulates the beam to allow phase sensitive lock-in amplification. The two-stage vacuum system used is similar in concept to the LIV system (shown in $\mathrm{fig}$. 2) but with a horizontal beampath geometry.

Vapor expansion experiments were conducted with $\mathrm{KCl}$ and $\mathrm{NaCl}$ vapor, in a $\mathrm{N}_{2}$ carrier gas, at source pressures of $-0.04 \mathrm{MPa}(0.4 \mathrm{~atm})$ and temperatures to $1300 \mathrm{~K}$. The data have been discussed in detail elsewhere [Hastie, et al., 1984], including a complete thermochemical analysis. Studies with variable pressure of nitrogen and orifice size were conducted to identify excess dimer/trimer formation due to possible clustering by expansion cooling. For the smaller orifice, (lower final beam temperature), the ion intensity ratio 
of dimer to monomer species decreased with increased $\mathrm{N}_{2}$ pressure (ie, decreased beam temperature), which indicated an absence of clustering . Similar results were found for the $\mathrm{NaCl}$ system.

One possible explanation for these results could be that higher molecular weight clusters fragment, thereby contributing to ion signals for the lower polymers. Our aralysis indicates, however, that such effects must be less than about 10 percent, as neither phase (time-of-flight) data nor appearance potentials show any evidence for unexplained contributions to assigned precursors. Similar arguments pertain to the $C_{n}$ system which also showed no evidence for cluster formation.

4. Subtask C: Results on Ionization Processes

In order to identify gaseous species in complex high temperature vapors, a mass spectrometer must be used to ionize and detect the neutrals. However, the electron impact ionization process frequently produces fragment ions. A universal assumption in high temperature mass spectrometry is that intensity ratios of fragment to parent ion are temperature independent, as might be argued from the thermal energy being negligible with respect to the ionizing energy. One known exception for high temperature species has been reported by Askishin et al., [1960] for the CsCl system, where a 20 percent variation in the ratio $\mathrm{Cs}^{+} / \mathrm{CsCl}^{+}$was observed over the temperature interval 800 to $900 \mathrm{~K}$. These authors argued that temperature-dependence in the Franck-Condon factors was the result of poor overlap between the ground state of $\mathrm{CsCl}$ with the bound ion state. Changes in the thermal population of the higher vibrational states with temperature would then influence the Franck-Condon factors. 
A relatively simple model of the temperature-dependent ionization process has been discussed by Dronin and Gorokov [1972], and also Nikolaev [1972]. Figure 8 shows a harmonic oscillator potential model for the ground state, located such that only a small overlap occurs with the stable region $\left(r>r_{c}\right)$ of the bound-ion state. The stable region is defined by vertical transitions (the Franck-Condon assumption for electron impact excitation) from the ground state to the ion-state region to the right of the internuclear distance where the ion dissociation limit intersects the ion-state repulsive wall, as shown in figure 8. The population fractions $f_{v}(T)$ of the various vibrational states can be determined, from which the fragmentation ratio can be calculated using the relationship:

$$
\text { - } R=M^{+} / M C I^{+}=\left(\sum_{V=0}^{\infty}\left[\int_{r_{C}}^{\infty}\left\{Y_{V}^{*} Y_{V} d r\right\} \cdot F_{v}(T)\right]-1\right)^{-1}
$$

where $Y_{V}$ is the vibrational eigenfunction for vibrational state $v$. From this expression, transitions from the ground state to the right of $r_{c}$ lead to parent ion formation, and transitions to the left of $r_{c}$ produce dissociation to fragments (see fig. 8). Although Nikolaev [1972] presented calculations of $r_{c}$, based on a model of the ion-state, he found it necessary to compute $r_{c}$ for CsCl empirically using the experimental fragmentation ratio. With this approach he obtained $r_{c}=0.342 \mathrm{~nm}$, compared to the calculated value of $0.323 \mathrm{~nm}$.

A more definitive, generally applicable model for this relatively novel process (for high temperature species) has been obtained under the present subtask using the TMS system. The isentropic expansion used to form a representative non-interacting beam from a high temperature region provides extreme rotational and vibrational cooling of the molecules. This cooling 
effect has led to observation of anomalously high ratios of $\mathrm{M}^{+} / \mathrm{MX}^{+}$in alkali halide species [Bonnell and Hastie, 1983]. The above model provides a basis for interpreting these experimental data since the proper temperature describing molecules in the beam is given by the isentropic temperature of the expansion rather than the source temperature. For suitable orifice dimensions, the temperature can be altered over a wide range by varying the system pressure. At high temperatures, the vibrational levels are significantly populated, up to $v=10$ or more. For the NaCl case, considered in detail here, less than half of the molecules at $800 \mathrm{~K}$ are in the $\mathrm{v}=0$ state (harmonic oscillator assumption); one percent, or more, occupancy is found up to the level $v=8$. It follows that an empirical interpretation based on the observed high temperature ratio is so insensitive to small changes in the value of $r_{c}$ that almost no information can be obtained from hot beams. Figure 9 shows a low temperature ionoratio limit near $8=27$ for the NaCl case (TMS data). For the harmonic oscillator fit, values of $\omega_{e}=363.62$ $\mathrm{cm}^{-1}$ and $r_{e}=0.23606 \mathrm{~nm}$ were used. Equation 4.1 was evaluated by numerical integration of harmonic oscillator ${ } v{ }^{\prime} s$ and direct summation over $v$ from 0 to 12. The evaluation was iterated on $\mathrm{r}_{\mathrm{c}}$ with $\mathrm{T}=10 \mathrm{~K}$ until the experimental value, $R=27 \pm 0.5$ was obtained and the corresponding value of $r_{c}$ was $0.24648 \pm 0.0001 \mathrm{~nm}$. Note that the high precision obtained for $r_{c}$ is indicative of the high sensitivity of this model approach. The temperaturedependence results based on this fit are plotted in figure 9 as the Harmonic Oscillator curve. It is clear that the qualitative shape of the data (including effusive measurements taken from the literature [BonneI] and Hastie, 1979]) is adequately modeled by the harmonic oscillator approximation. But even with a possible error of a factor of two in beam temperature (which has been applied to the data), the model does not quantitatively 
fit either the TMS or KMS effusive data. A likely explanation of the model's deficiency is that the ground state well is anharmonic, and the harmonic oscillator eigenvalues of the levels underestimate upper level participation. The curve labeled High Temp. Fit in figure 9 is based on a harmonic oscillator-model calculation, made using only the high temperature effusion data. Note the disagreement of this model approach with that using the low temperature (EXPANSION) data. This difference indicates the impossibility of successfully modeling temperature dependent fragmentation based only on high temperature data. Also, the extreme sensitivity of the model prediction on the value of $r_{c}$ is demonstrated by comparison of the high temperature $f$ it and low temperature anharmonic oscillator results, shown in figure 9 . This sensitivity indicates that low temperature ion-intensity data can provide a stringent test of ground state potential well shape, particularly for levels above the ground vibrational state.

The basis for the anharmonic model used is as follows. The potential well was computed by the Rydberg-Klein-Rees method from the spectroscopic data selected by JANAF $[1971]: \omega_{e}=363.62, \omega_{e} x_{e}=1.72, B_{e}=0.21691$, a11 in $\mathrm{cm}^{-1}$. These values imply $\mathrm{r}_{\mathrm{e}}=0.23679 \mathrm{~nm}$. The function, $\mathrm{f}_{\mathrm{V}}(\mathrm{T})$ was summed directly from the anharmonic eigenvalues

$$
E_{v}=\omega_{e}(v+1 / 2)-\omega_{e} x_{e}(v-1 / 2)^{2}
$$

normalized by summing to $\mathrm{v}=15$ where the population, even at $1200 \mathrm{~K}$, was insignificant. The anharmonic eigenfunctions were approximated by mapping harmonic oscillator eigenfunctions onto the actual potential well. Figure 9 shows the resulting model behavior for $R$ with $T$, given as the Anharmonic 
Osciliator curve $\left(r_{c}=0.2445=0.0001 \mathrm{~nm}\right)$. The model agreement with the TMS data is now excelient; however, the model stili fails to predict the elfusive KMS data. Possible explanations are:

- Harmonic osciliator eigenfunctions are not a good model at high temperature--the "true" eizenfunctions do exhibit higher amplitude toward the right wall of an annarmonic potential than toward the left.

- Centrifugal broadening of the potential-well and high rotational level occupation may be important in the calculation--at $\mathrm{T}>800 \mathrm{~K}, \mathrm{~J}(\max )$ is of the order of 60 ; the effect on $f_{V}(T)$ and $Y_{V}$ may be more significant than the effect on the potential well.

- Avoided-crossing distortions of the potential-well may be important at high temperatures although Oppenheimer and Berry [1971] calculate that point for $\mathrm{NaCl}$ to be at $r=0.94 \mathrm{~nm}$, where no significant thermal occupation would exist.

- The actual form of the potential may not be accurate enough above $v=2-3$

- The separation of the two states of the ion, expected to exist, may cause the simple overlap model to fail at higher temperatures. An abinitio calculation for this problem is now possible and probably warranted. However, many important systems are not yet calculable, and fragmentation at a single bond is a very important case. The sensitivity shown by this model also points to the possibility of directiy using this effect to test existing abinitio calculations of the higher energy levels. 
Akishin, P. A., Gorokov, L. N., and Sidorov, L. N. [1960]. Proc. Acad. Sci. USSR. (Dok. Phys. Chem.) 135, 1001.

Baker, R. L., Covington, M.A., and Rosenblatt, G. M. [1983]. "The Determination of Carbon Thermochemical Properties by Laser Vaporization". P. 143 in High Temperature Materials Chemistry, Eds. Munir, Z. A., and Cubicciotti, D., Electrochem. Soc., Pennington, $\mathrm{NJ}$.

Berkowitz, J., and Chupka, W. [1964]. J. Chem. Phys. 40, 2735.

Bonnell, D. W., and Hastie, J. W. [1979]. P. 357 in Characterization of High Temperature Vapors and Gases, J. W. Hastie, ed., NBS SP 561, U.S. Govt. Printing office, Washington, $D C$.

Bonnell, D. W., and Hastie, J. W. [1983]. A Theoretical Analysis of Temperature Dependent Electron Impact Fragmentation, $31 \mathrm{st}$ Ann. Meeting, Amer. Soc. Mass Spec., Boston.

Clarke, J. J., and Fox, B. R. [1969]. J. Chem. Phys. 51, 3231.

Covington, M. A., Liu, G. N., and Lincoln, K. A. [1977]. AIAA J. 15, 1174.

Dronin, A. A., and Gorokov, L. N. [1972]. Teplofiz. Vys. Temp. 10, 49.

Drowart, J., Burns, R. P., De Maria, G., and Inghram, M. G. [1959]. J. Chem. Phys. 31, 1131 .

Eesenko, V. V., and Bolgar, A. S. [1969]. Teplofiz. Vys. Temp. $1,244$.

Gupta, S. K., and Gingerich, K. A. [1979]. J. Chem. Phys. 71, 3072.

Hall, R. [1984] Private Communication.

Hastie, J. W., Zmbov, K. F., and Bonnell, D. W., [1984]. "Transpiration Mass Spectrometric Analysis of Liquid KCl and $\mathrm{KOH}$ Vaporization," High Temp.

Science, in press.

"JANAE Thermochemical Tables", 2nd ed., NSRDS-NBS 37 (Washington, DC, 1971).

Leider, H. R., Krikorian, O. H., and Young, D. A. [1973]. Carbon 11, 555 .

Lincoln, K. A. [1969]. P. 323 in "High Temperature Technology," Butterworths and Co., London.

Lincoln, K. A., and Covington, M. A. [1975]. Int. J. Mass Spec. Ion Phys. 16,191 .

Lundell, J. H., and Dickey, R. R. [1977]. Progr. Astron. and Aeron. 56, 405. Lunde11, J. H. [1982]. Progr. Astron. and Aeron. 83, 472. 
Meyer, R. T., and Lynch, A. X. [1973]. Hizh Temp. Science 5, 192.

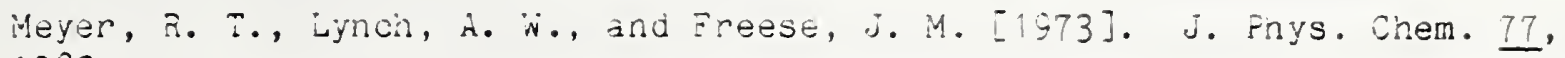
1083.

Milne, T. A., Beachey, J. E., and Greene, F. T. [1972]. In "Vaporization Kinetics and Thermodynamics of Graphite Using the High Pressure Mass Spectrometer." AFML-TR-72-227 (AD 753713).

Nikolaev, E. N. [1972]. Khim. Yys. Energil, 2, 49.

Ohse, R. W., Babelot, J. F., Cercignani, C., Kinsman, P. J., Lons, K. A., Magill, J., and Scotti, A., [1979]. P. 83 in Characterization of High Temperature Vapors and Gases, J. W. Hastie, ed., NBS SP 561, U.S. Govt. Printing office, Washington, DC.

Olstad, R. A., and Olander, D. R. [1975]. J. Appl. Phys. 46, i509.

Oppenheimer, M., and Serry, R. S. [1971]. J. Chem. Phys., 54, 5058.

Palmer, H. B., and Shelef, M. [1968]. Carbon 4 , 85.

Sterns, C. A., Kohl, F. J., Fryburg, G. C., and Miller [1979]. P. 303 in Characterization of High Temperature Vapors and Gases, J. W. Hastie, ed., NBS SP 561, U. S. Govt. Printing Office, Washington, DC

Strauss, H. L., and Thiele, E. [1967]. J. Chem. Phys., 46, 2473.

Thorn, R. J., and Winslow, G. H. [1957]. J. Chem. Phys. 26, 186.

Wachi, E. M., and Gilmartin, D. E. [1970]. Carbon 8, 141.

Wulfson, E.K., Dworkin, W.I., and Karjakin, A.W. [1980]. Spectrochim. Acta 35B, 11 .

Zavitsanos, P. D., [1968]. Carbon 6, 731 .

Zavitsanos, P. D., and Carlson, G. A. [1973]. J. Chem. Phys. 59, 2966. 
Table i. $C_{n}$ Ion Intensities and Corresponding Calculated Equilibrium Surface Temperaturesa

\section{Ionizing electron energy $=96 \mathrm{eV}$}

Mass (am) Species Peak Signal Integrated Signal Temperature (K)

$\begin{array}{llllr}12 & c_{1} & 0.51 & 0.32 & 2600 \\ 24 & c_{2} & 0.16 & 0.12 & 3450 \\ 36 & c_{3}^{2} & 1.0 & 1.0 & --- \\ 48 & c_{4} & 0.015 & 0.018 & 4400 \\ 50 & C_{5} & 0.04 & 0.04 & 4300\end{array}$

Ionizing electron energy $=26 \mathrm{eV}$

$\begin{array}{llllr}12 & c_{1} & 0.47 & 0.32 & 2600 \\ 24 & c_{2} & 0.14 & 0.11 & 3200 \\ 36 & c_{3} & 1.0 & 1.0 & -- \\ 48 & C_{4} & 0.014 & 0.013 & 4100 \\ 50 & C_{5} & 0.027 & 0.027 & 4000\end{array}$

The accuracy of the $C_{1}$ and $c_{2}$ ratios to $C_{3}$ is about 30 and 10 percent, respectively; for $\mathrm{C}_{4}$ and $\mathrm{C}_{5}$ the accuracy is about 25 percent. Typical $C_{3}$ signals are 100 to $200 \mathrm{mv}$ peak.

bobtained by comparison of observed Integrated Signal intensities, relative to $C_{3}$, with the JANAF [1971] thermochemical partial pressure data.

Table 2. Surface Temperature Results in the Graphite System

Method

$\mathrm{C}_{2}{ }^{+}$arrival time relative to $\mathrm{B}^{+}$(at $2900 \mathrm{~K}$ )

${ }^{P} C$ from $P=k I\left(C^{+}\right) T$, with JANAF [1971]

$\mathrm{C}^{+} / \mathrm{B}^{+}$intensity ratio (for $\mathrm{B}$ at $2900 \mathrm{~K}$ )

$c_{4}$ (or $\left.C_{5}\right) / C_{3}$, with JANAF [1971]
Temperature $(K)$

$$
\begin{aligned}
& 4000 \pm 300 \\
& 4200 \pm 300 \\
& 4100 \pm 300 \\
& 4100 \pm 300
\end{aligned}
$$

$\overline{\text { Average }} \quad \overline{4100 \pm(300)}$


Table 3. Comparison of Present Results with Zavitsanos [1968] Ion Intensities, Normalized to $\mathrm{C}_{3}$ at $4100 \mathrm{~K}$

$\begin{array}{lcc}\text { Ion } & \text { Zavitsanos }(20 \mathrm{ev}) & \text { This Work }(26 \\ C_{1} & 0.48 & 0.47 \\ c_{2} & 1.00 & 0.14 \\ C_{3} & 1.00 & 1.0 \\ C_{4} & 0.24 & 0.014 \\ c_{5} & 0.39 & 0.027 \\ c_{6} & 0.15 & <0.01 \\ c_{7} & 0.16 & -0-\end{array}$

Table 4. Comparison of Present Ion Intensity Results with the Milne et al., [1972] Extrapolated Ion Ratios at $4200 \mathrm{~K}$, Normalized to $\mathrm{C}_{3}$

JANAF [1971] Pressure (atm) Milne, et al. [1972] This Work (26eV)

\begin{tabular}{llll}
$c_{3}$ & 2.5 & 1.0 & 1.0 \\
$C_{1}$ & 0.2 & $0.08(=$ JANAF $)$ & 0.32 \\
$c_{2}$ & 0.3 & $0.12(=$ JANAF $)$ & 0.11 \\
$c_{4}$ & 0.3 & 0.12 & 0.013 \\
$c_{5}$ & 0.3 & 0.12 & 0.027 \\
$C_{6}-c_{7}$ & 0.001 & 0.0004 & $<0.01$ \\
\hline
\end{tabular}


Table 5. Temperatures Calculated from Partial Pressure Ratios, Relative to $\mathrm{C}_{3}$

\begin{tabular}{|c|c|c|c|c|}
\hline Species & $\begin{array}{l}\text { Ion Intensities } \\
\text { [This Work, } 96 \mathrm{eV}]\end{array}$ & $\begin{array}{l}\text { Temp. K } \\
\text { [JANAE] } \\
\end{array}$ & $\begin{array}{l}\text { Relative Pressures } \\
\text { [Meyer and Lynch] }\end{array}$ & $\begin{array}{l}\text { Temp. K } \\
\text { [Meyer and Lynch] }\end{array}$ \\
\hline$c_{1}$ & 0.32 & 2600 & 0.1 & $>5000$ \\
\hline$c_{2}$ & 0.12 & 3450 & 0.13 & 3500 \\
\hline$c_{3}$ & 1.0 & -- & 1.0 & $-\infty$ \\
\hline$C_{4}$ & 0.018 & 4400 & 0.046 & $>5000$ \\
\hline$c_{5}$ & 0.04 & 4300 & 0.094 & $>5000$ \\
\hline
\end{tabular}


SIGNAL AVERAGER

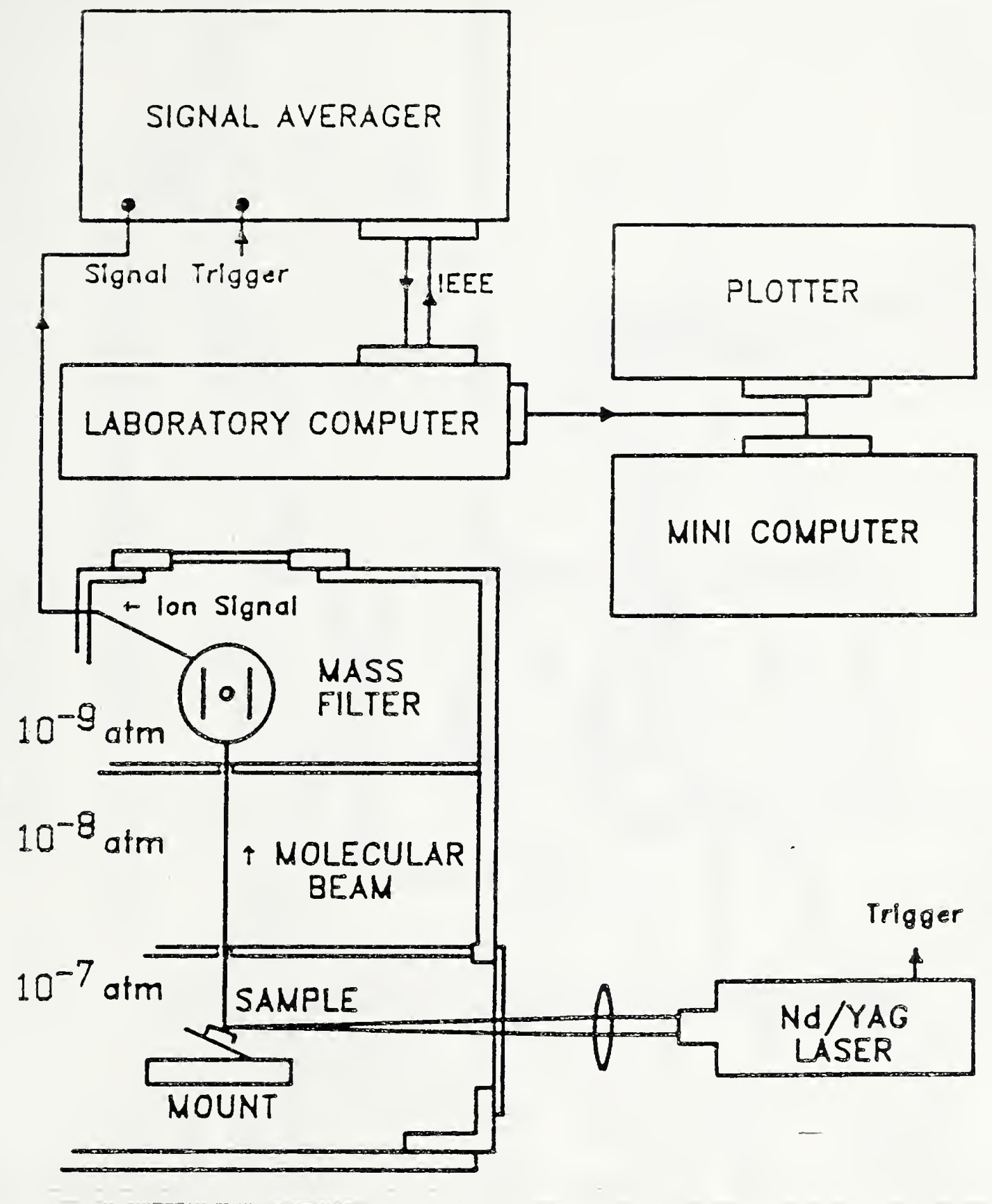

Figure 1. Schematic of laser-induced vaporization mass spectrometric facility (side view), showing laser-sample-molecular beam geometries. The microcomputer system shown controls the signal averager and records completed scans. 


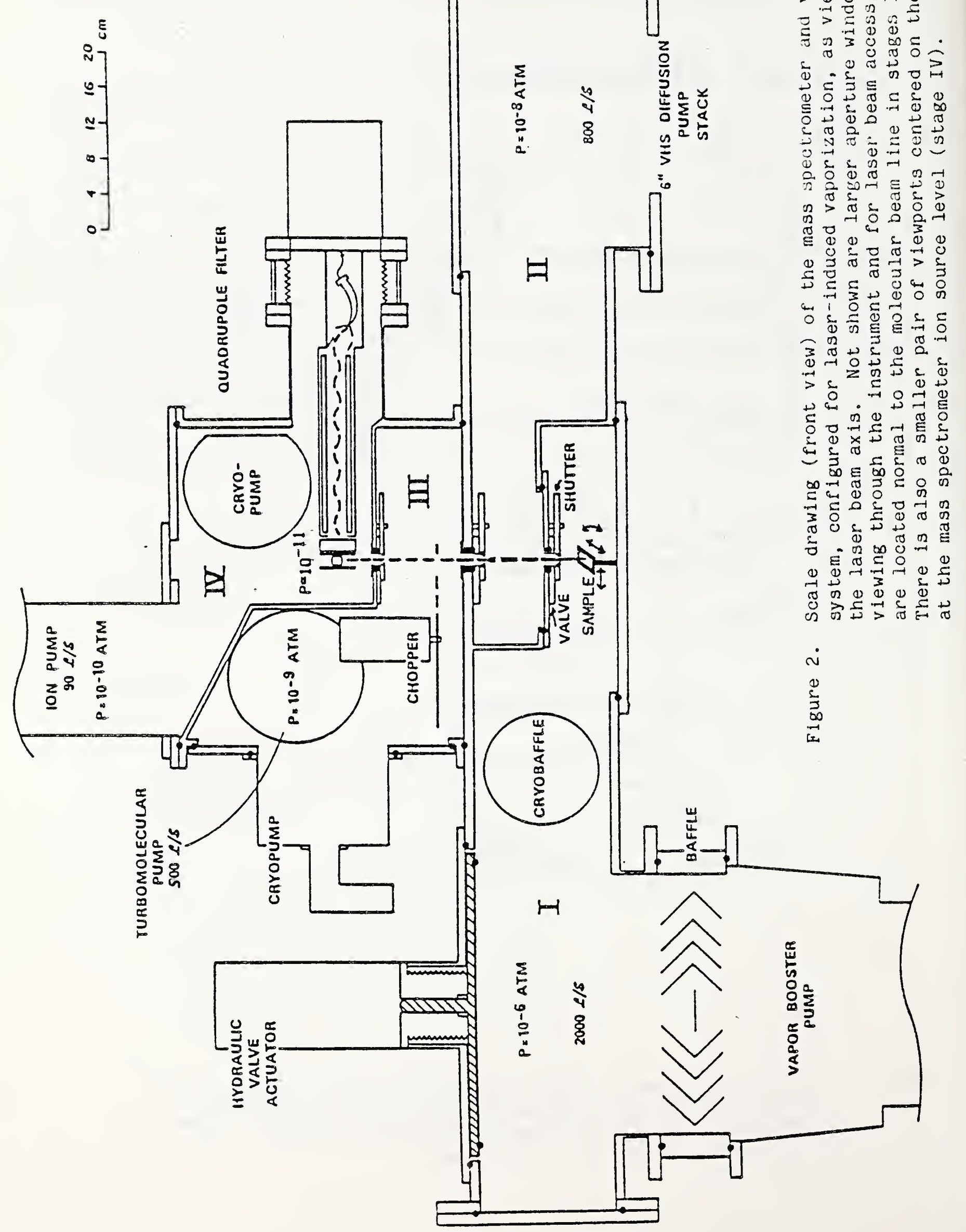




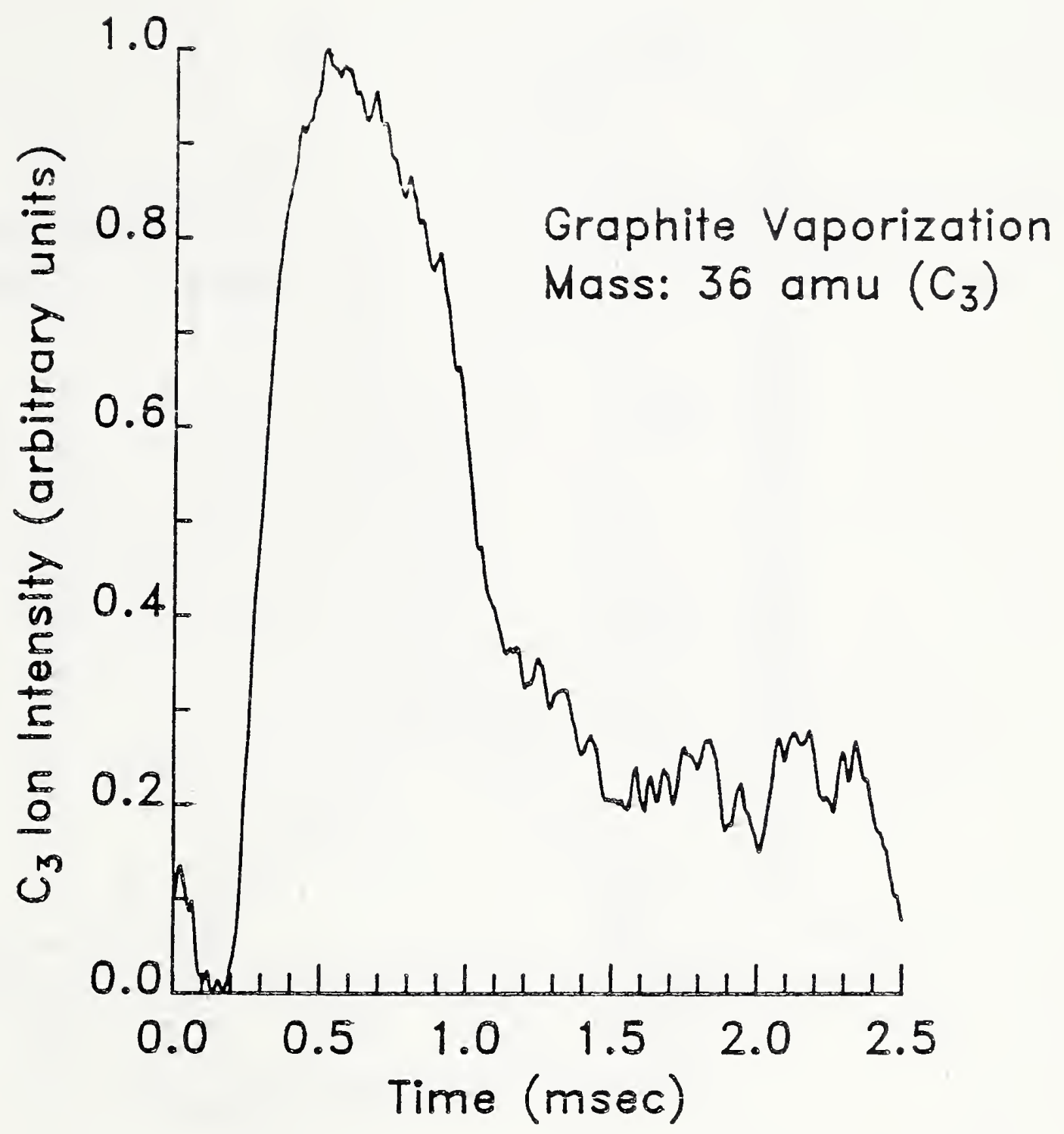

Eigure 3. Mass spectral ion intensity-versus-time profile for the 36 amu $\left(\mathrm{C}_{3}{ }^{+}\right.$) ion at $30 \mathrm{eV}$ nominal ( $26 \mathrm{eV}$ actual) ionizing electron energy. Unit peak-ion-intensity equals 27336 counts. 


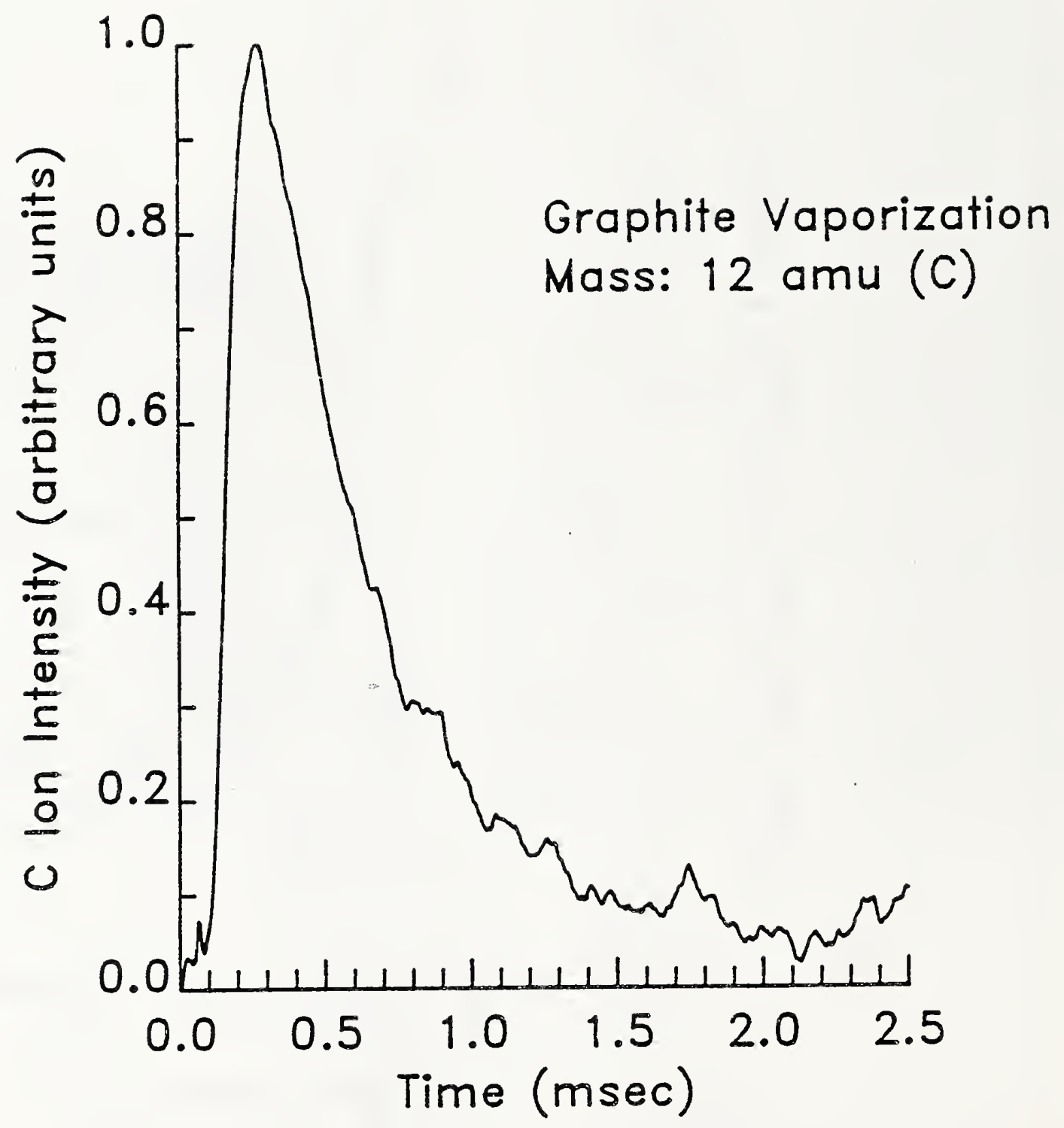

Figure 4. Mass spectral ion intensity-versus-time profile for the 12 amu $\left(\mathrm{C}_{1}{ }^{+}\right.$) ion at $30 \mathrm{eV}$ nominal ( $26 \mathrm{eV}$ actual) icnizing electron energy. Unit peak-ion-intensity equals 30551 counts. 


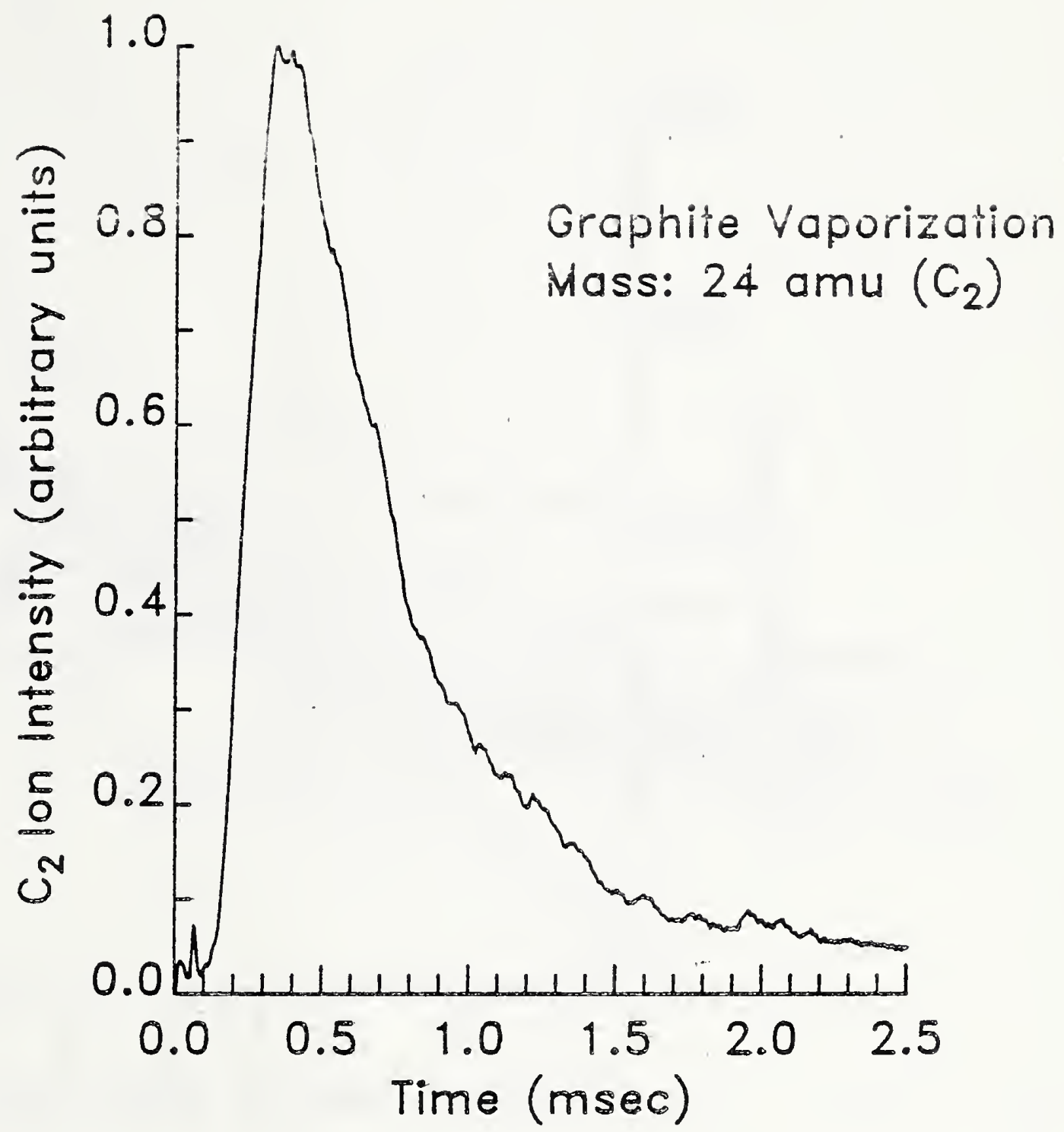

Figure 5. Mass spectral ion intensity-versus-time profile for the 24 amu $\left(\mathrm{C}_{2}^{+}\right)$ion at $30 \mathrm{eV}$ nominal ( $25 \mathrm{eV}$ actual) ionizing electron energy. Unit peak-ion-intensity equals 20337 counts. 


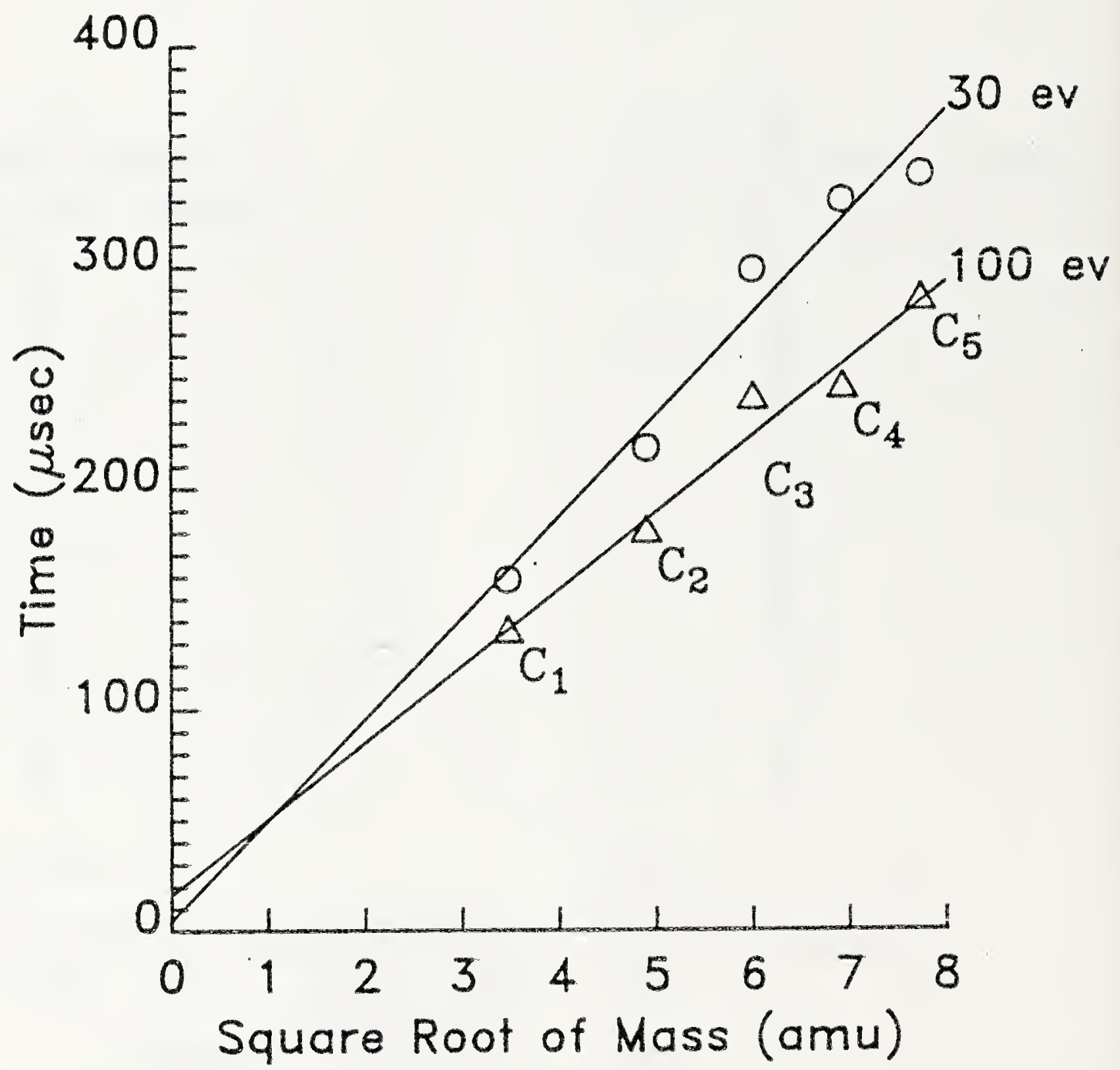

Figure 6. Dependence of the time-of-arrival for $C_{n}{ }^{+}(n=1$ to 5$)$ ions as a function of rolecular weight from laser vaporized graphite. The linear dependence confirms the assignment of neutral precursors, and indicates a common thermal source and local thermal equilibrium. The two curves shown are for $30 \mathrm{eV}$ and $100 \mathrm{eV}$ nominal ionizing electron energy data sets. 


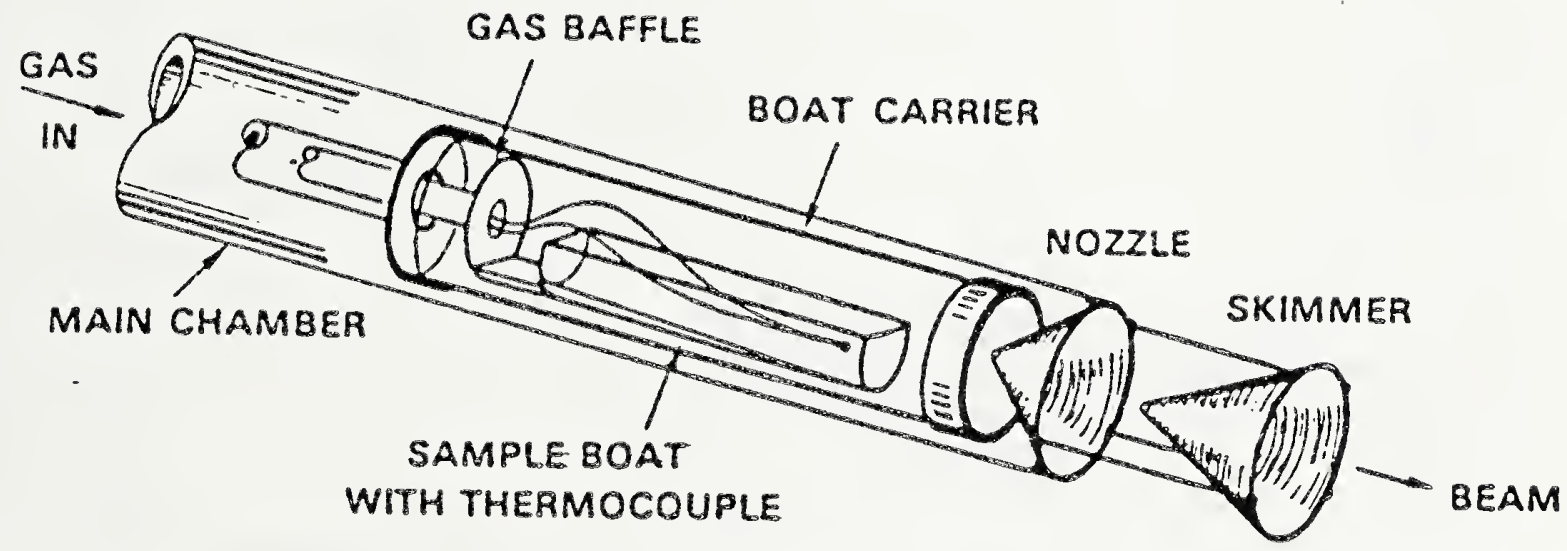

Eigure 7. The Transpiration Mass Spectrometer Inlet System. 


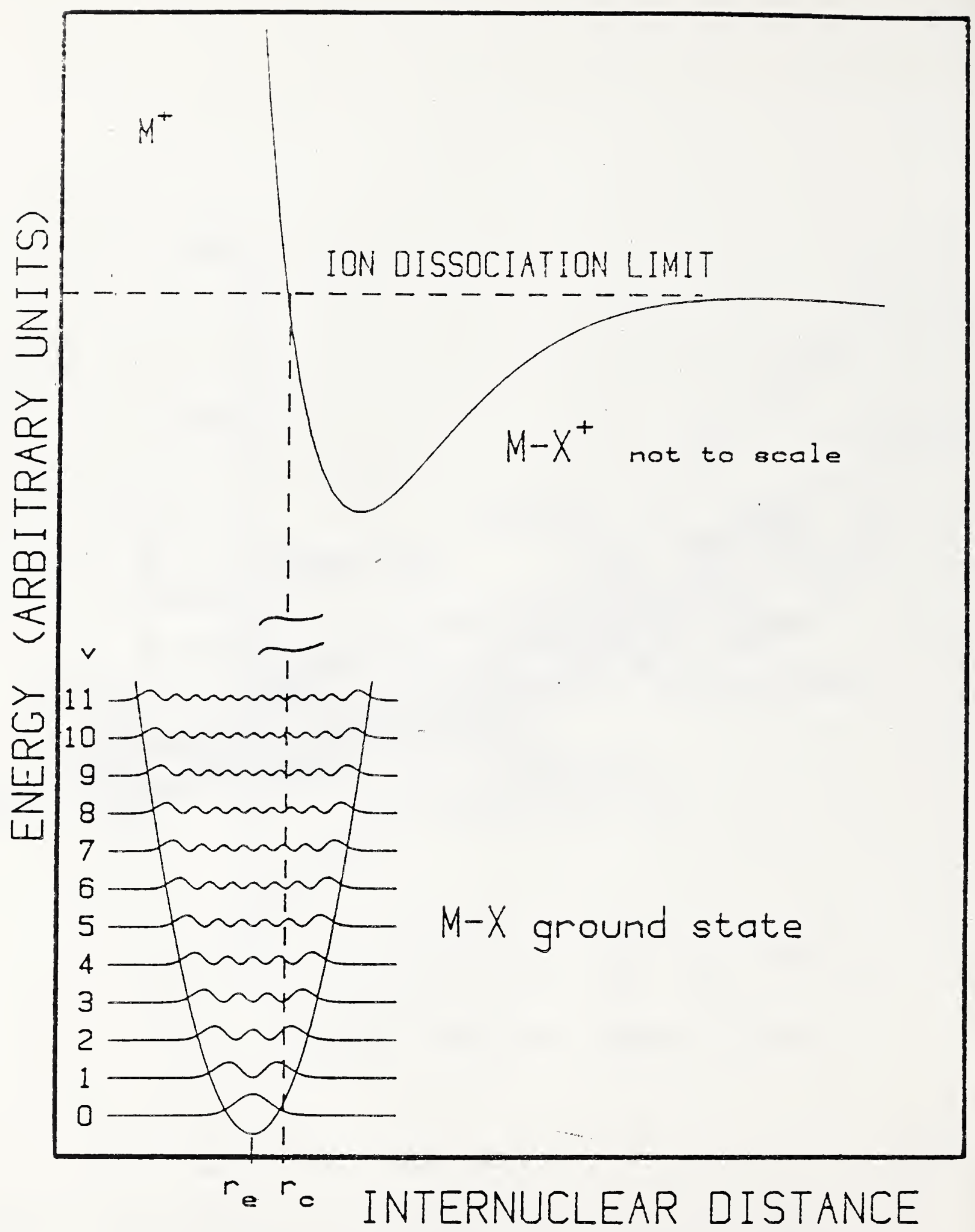

Figure 8. Temperature-dependent electron impact fragmentation model. The lower potential well is for a harmonic oscillator with the probability density functions (square of harmonic oscillator eigen-functions) drawn to scale; $r_{e}$ is the equilibrium internuclear distance, and $r_{c}$ represents the dividing line between vertical (Franck-Condon) transitions to a bound molecular ion (at $r>r_{c}$ ) and to an unstable condition (at $r<r_{C}$ ) giving fragmentation. 


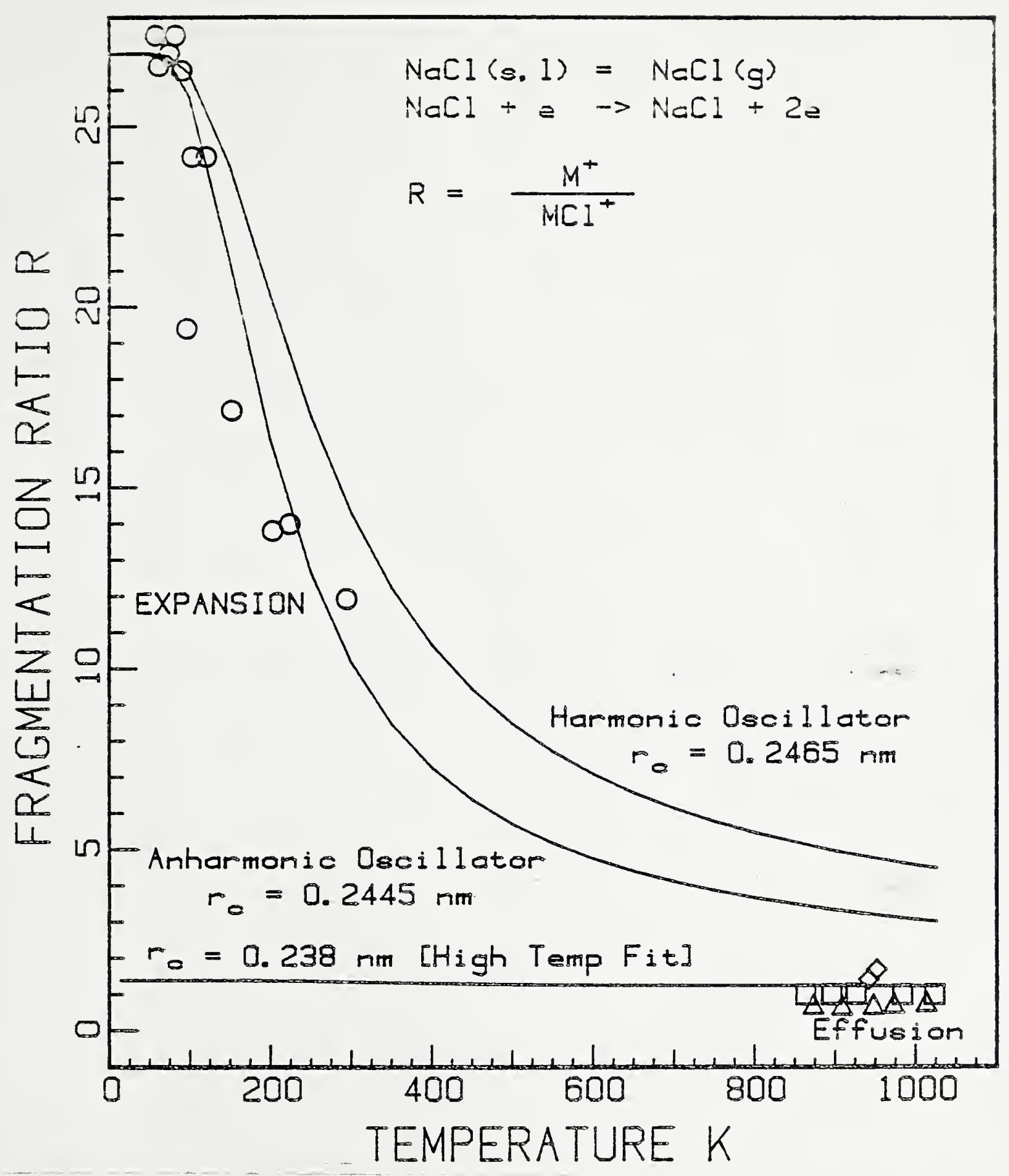

Figure 9. Comparison of experimental and model fragmentation ratios in high pressure expansions of $\mathrm{NaCl}$ vapor $-\mathrm{N}_{2}$ gas mixtures. The temperature axis was derived from the source pressure using an isentropic expansion/sudden-freeze model (see for instance, Stearns, et al., 1979). An expansion effectiveness parameter of 0.5 has been applied to the derived $\mathrm{T} / \mathrm{T}_{0}$. The $\mathrm{r}_{\mathrm{c}}$ value labeled High Temp. Fit is for a harmonic oscillator calculation, using only experimental high temperature $\mathrm{R}$-data (see text). 


\begin{tabular}{|c|c|}
\hline 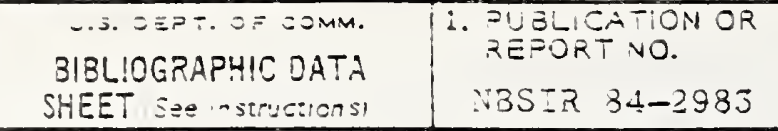 & $\begin{aligned} \text { 2. Pertorming Orzan. Report Vo. } \begin{array}{r}\text { 3. Pudication Date } \\
\text { December } 1984\end{array}\end{aligned}$ \\
\hline \multicolumn{2}{|l|}{$\begin{array}{l}\text { 4. T!TLE ANO SUST:TLE } \\
\text { Golecular Basis for iaser-Induced V }\end{array}$} \\
\hline \multicolumn{2}{|c|}{ 5. AUTHOR(S) } \\
\hline \multirow[t]{2}{*}{ 5. PERFORMING ORGANIZATION $1:$ j oint or other th } & $\begin{array}{l}\text { 7. Contraej Grant No. } \\
\text { AFOSR-ISSA-34-00033 }\end{array}$ \\
\hline & $\begin{array}{l}\text { 3. Tyoe of Reoort \& Period Covered } \\
\text { Annual FY84 }\end{array}$ \\
\hline \multicolumn{2}{|c|}{$\begin{array}{l}\text { 9. SFONSCRING ORGANIZATION NAME AND COMPLETE AODRESS (Street. City. SLOte, ZIPI } \\
\text { AFOSR/NE } \\
\text { Electronic \& Material Science Directorate } \\
\text { BOIling AEB }\end{array}$} \\
\hline
\end{tabular}

10. SUPPLEMENTARY NOTES

Document describes a comouter program: SF-185, FIPS Sofeware Summary, is attached.

11. ABSTRACT (A 200-word or iess faciual summary of mose significant information. If document includes a significant bibliograpny or literoture survev, mention it herel

A new technique has been developed for time-resolved Laser Induced Vaporization (III) studies. of reprectory materials. The apparatus consists of a high power 10 Hz, pulsed Nd/YAG laser coupled to a spectally designed high pressure sampling rass spectrometer. Initial studies on an ultra-pure spectroscopic grade graphite sample provided time-resolved quantitative mass spectral peaks, corresponding to $C_{n}$ ( $\Omega=1$-5) molecular species, with excelient simal-to-noise and reproducibility. The absolute and relative intensities of these species were consistent with the establishment of thermodynamic equilibrium at the sample surface. A beam-velocity analysis of the C species indicated an appreclable cooling effect in the rapor plume by an adiabatic expansion process. In a separate study, attempts to produce molecular clusters by non-equilibrium adiabatic expansion of $\mathrm{NaCl}, \mathrm{KCl}$, and $\mathrm{C}_{n}$ ( $\mathrm{I}$ 5) molecular $\mathrm{species}$ showed no evidence ol clustering at source vapor pressures to one atmosphere. This result sets limits on the expansion times, source pressure, and temperature conditions needed to produce ciuster species for these systans. Ne have also found that relative ionization cross-sections $(\sigma)$ can vary quite significantly with temperature, particularly for species exhibiting a large geometry change on ionization. Data obtained for the test systems, NaCl and XCl, exhibited large changes in $\sigma$ (25:1) between high temperature (- $1000 \mathrm{~K}$ ) species and translationally coolad low temperature ( $-50 \mathrm{~K}$ ) molecules. The results are quantitatively explained by a potential energy curve model.

12. KEY WORDS (Six to twelve entries; alonobetical order: caoitclize oniy proper nomes: and seoarate key words by semicolons) arhármonic, jeam velocity, electron impact ionization cross-sections, expansion cooling graphite, high temperature, laser heating, mass spectrometry, osciliator model, supersonic molecular beam, temperature dependent eragmentation, vaporization 13. AVAILABILITY

Order From Suderintendent of Documents, U.S. Government Princing Office, Washington, O.C. 20402 .

14. NC. OF PRINTED PAGES 48

15. Price $\$ 8.50$ 

